\title{
DSMC SIMULATIONS OF BLUNT BODY FLOWS FOR MARS ENTRIES: MARS PATHFINDER AND MARS MICROPROBE CAPSULES
}

\author{
James N. Moss* , Richard G. Wilmoth ${ }^{\dagger}$ and Joseph M. Price \\ NASA Langley Research Center \\ Hampton, Virginia
}

\begin{abstract}
The hypersonic transitional flow aerodynamics of the Mars Pathfinder and Mars Microprobe capsules are simulated with the direct simulation Monte Carlo method. Calculations of axial, normal, and static pitching coefficients were obtained over an angle of attack range comparable to actual flight requirements. Comparisons are made with modified Newtonian and free-molecular-flow calculations. Aerothermal results were also obtained for zero incidence entry conditions.

\section{NOMENCLATURE}

$\begin{array}{ll}a & =\text { acceleration } \\ C_{A} & =\text { axial force coefficient } \\ C_{D} & =\text { drag coefficient } \\ C_{H} & =\text { heat transfer coefficient } \\ C_{i} & =\text { mass fraction of species } i \\ C_{N} & =\text { normal force coefficient } \\ C_{m, c g} & =\text { pitching moment coefficient about center } \\ C_{m, o} & =\text { pitching moment coefficient about nose } \\ d & =\text { maximum probe diameter } \\ K n & =\text { Knudsen number } \\ p & =\text { pressure } \\ q & =\text { heat transfer rate } \\ R_{a} & =\text { afterbody radius } \\ R_{b} & =\text { maximum probe radial dimension } \\ R_{c} & =\text { comer radius }\end{array}$
\end{abstract}

\footnotetext{
"Aerospace Engineer, Aerothermodynamics Branch, Aero- and Gas-Dynamics Division, Fellow AIAA.

${ }^{\dagger}$ Aerospace Engineer, Aerothermodynamics Branch, Aero- and Gas Dynamics Division, Senior Member AIAA

${ }^{\ddagger}$ Aerospace Engineer, Aerothermodynamics Branch, Aero- and Gas Dynamics Division.

Copyright ( 1997 by the American Institute of Aeronautics and Astronautics, Inc. No copyright is asserted in the United States under Title 17, U. S. Code. The U. S. Government has a royalty-free license to exercise all rights under the copyright claimed herein for Government purposes. All other rights are reserved by the copyright owner.
}

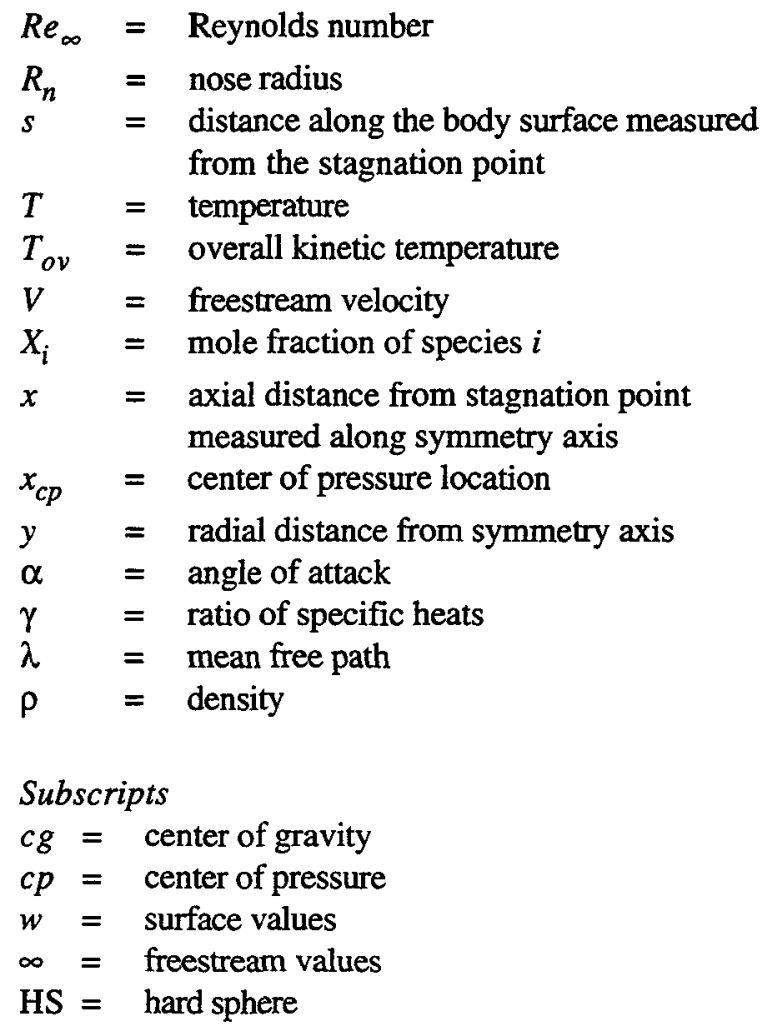

\section{INTRODUCTION}

During the next decade, mapping and inspection missions to Mars will occur with considerable frequency utilizing orbiters, landers and penetrators. The NASA Planetary Exploration Program plans for a pair of spacecraft to be sent to Mars every twentysix months for the next five years. This activity was initiated in late 1996 with two successful launches: first, the Mars Global Surveyor spacecraft which will provide an orbiting platform and, second, the Mars Pathfinder scheduled for a Mars landing July 4, 1997.

The Mars Pathfinder mission will demonstrate a low-cost delivery system ${ }^{1,2}$ to the surface of Mars while providing unique opportunities for scientific exploration. The entry vehicle contains a scientific instrument platform and a small rover that will be placed on the surface of Mars. Pathfinder is viewed as 
a proof-of-concept system for future Mars explorations such as the Mars '98 Surveyor Lander mission which will include an orbiter and a lander and the Mars 2001 Aerocapture Orbiter, again an orbiter and a lander. The entry and aerocapture capsules for the later missions will be similar to the Pathfinder configuration. In addition, the Mars ' 98 mission will deploy two Mars Microprobes, penetrators that are enclosed in basketball size aeroshells for thermal protection and stabilization during entry.

The present study addresses the rarefied aerodynamics of two of the Mars entry capsulesPathfinder and Mars Microprobes. As demonstrated in the present paper, rarefied aerodynamics can be a significant issue for entry capsules, particularly those without an active control system as is the case for both Pathfinder and the Mars Microprobes. Since rarefied aerodynamic databases are required for design, operations and postflight analyses, results of numerical simulations are presented. The simulations are achieved with the direct simulation Monte Carlo (DSMC) method of Bird ${ }^{3}$. DSMC results obtained using both axisymmetric and three-dimensional solvers are presented and complemented with free molecular and Newtonian results.

The Mars Pathfinder capsule has a $70.19^{\circ}$ spherically blunted forebody followed by a $46.63^{\circ}$ conical afterbody with a maximum diameter of $2.65 \mathrm{~m}$. Because of Pathfinder's aft center-of-gravity location, it is statically unstable for the free molecular and much of the transitional flow regime, that is, the flow regime bounded by free molecular and continuum flow. However, as shown from trajectory calculations, the gyroscopic effect of the vehicle spin is adequate for preventing unacceptable increases in vehicle attitude during the transitional portion of entry. A second requirement for Pathfinder rarefied aerodynamics is to support the atmospheric structure experiment where data obtained from accelerometer measurements will allow the extraction of atmospheric density as well as pressure and temperature. Accuracy of the atmospheric structure experiment depends directly on the accuracy of the probe axial force coefficients.

Upon arrival at Mars, the Microprobes will be released from the Surveyor spacecraft and begin a free fall to the surface. The capsule forebody is a spherically blunted $45^{\circ}$ half angle cone followed by a hemispherical backshield with a maximum body diameter of $0.35 \mathrm{~m}$. A unique aspect of the Microprobes' entries is that the vehicles will encounter Mars' outer atmosphere in a random state, potentially tumbling after deployment from their host Mars '98 lander. The Microprobes are dependent on transitional flow aerodynamics to achieve an orientation such that the afterbody thermal protection system is not compromised by heating at or near continuum flow conditions. Therefore, aerodynamic data for zero-to-large angles of incidence are provided for selected degrees of rarefaction. A discussion of the rationale for selection of the Mars Microprobes aeroshell shape is given in Ref. 4 along with a description of its current aerodynamic database that includes hypersonic rarefied, hypersonic continuum, supersonic and transonic flow regimes.

\section{COMPUTATIONAL METHODS AND PHYSICAL MODELS}

The computational tools utilized consisted of two DSMC codes complemented with a free molecular/Newtonian code. The G2 code of $\mathrm{Bird}^{5}$, a 2D/axisymmetric code, was used to provide zero incidence DSMC calculations. G2 utilizes a bodyfitted grid and has an extensive history of application and validation. For a G2 simulation, the computational domain can be subdivided into an arbitrary number of unstructured regions, each region further subdivided into structured but variable size cells, and the cells subdivided into subcells to promote nearest neighbor collisions.

The 3D DSMC calculations were made using the code of LeBeau (described in Ref. 6) named DAC (DSMC Analysis Code). DAC uses a variableresolution Cartesian grid currently consisting of two levels of cells. The resolution of the first level of cells is constant and is typically set based on the minimum desired flowfield resolution for a given problem. To further refine the flowfield grid in areas of increased density or high gradients, each level-1 cell can have an additional level of embedded Cartesian refinement. This second level of refinement is independent for each level- 1 cell. The ability to refine the flowfield grid locally allows DAC to meet the spatial resolution required without excessive global refinement. The surface geometry for DAC is specified as a collection of planar triangular elements which form an unstructured triangular grid. The surface grid is defined independently of the volume grid. The reduced volumes of Cartesian cells that are clipped by the surface are computed and, to minimize the computational effort required to determine molecule-surface interactions, the surface triangles are mapped to the Cartesian cells. Uncoupling the surface and volume grids is a desirable feature when calculating aerodynamic moments particularly for highly rarefied flows in that the surface discretization 
can be resolved sufficiently to achieve accurate moment calculations without unnecessary flowfield resolution. More details concerning DAC features and capabilities are included in Ref. 6. An example of the good agreement between G2 and DAC for blunt body aerodynamics is discussed in Ref. 7 where the rarefied aerodynamics for the Galileo Probe $\left(45.14^{\circ}\right.$ spherically blunted forebody with a hemispherical afterbody and a maximum diameter of $1.265 \mathrm{~m}$ ) were calculated.

Free molecular and Newtonian values presented herein were calculated using the DACFREE code. This code was written by the second author utilizing free molecular ${ }^{3}$ and modified Newtonian ${ }^{8}$ analytical expressions. An unstructured triangular surface grid is used to define the surface geometry, the same as used to define the surface geometry in DAC.

For both DSMC codes, the physical models are common. Molecular collisions are simulated using the variable hard sphere (VHS) ${ }^{3}$ molecular model. Energy exchange between kinetic and internal modes is controlled by the Larsen-Borgnakke ${ }^{9}$ statistical model. A rotational relaxation collision number of 5 and a vibrational collision number of 50 were used. Solutions were obtained with and without chemical reactions for a constant freestream gas composition consisting of 97 percent $\mathrm{CO}_{2}$ and 3 percent $\mathrm{N}_{2}$ by mass. Parameters used to define the VHS model were a reference temperature of $3000 \mathrm{~K}$ and a temperature exponent of viscosity of 0.8066 .

For the calculations made with a reacting chemistry model, an updated version of the reaction set (54 reactions) utilized in the study by Hash and Hassan ${ }^{10}$ was employed. This model consisted of eight species $\left(\mathrm{O}_{2}, \mathrm{~N}_{2}, \mathrm{O}, \mathrm{N}, \mathrm{NO}, \mathrm{C}, \mathrm{CO}\right.$, and $\left.\mathrm{CO}_{2}\right)$ while accounting for dissociation (40) and exchange (14) reactions.

The surface boundary conditions assumed the gassurface interaction to be diffuse with full thermal accommodation to a specified surface temperature. For those calculations with reacting chemistry, the surface was assumed to be noncatalytic.

Representative examples of DSMC validation for blunt body hypersonic flows are given in Refs. 11 through 13 where the test cases are closely related to the Pathfinder configuration. Several examples of applications of the $\mathrm{G} 2$ code of Bird to simulate ground based experiments performed as part of the AGARD Working Group 18 activity are included in Refs. 11 and 12. These test cases span a range of conditions (nonreacting to reacting flows) in the transitional to continuum regime. Comparisons of measurements and computations include flowfield structure, surface quantities and aerodynamics. In general, the $\mathrm{G} 2$ results were in good agreement with the measurements. Also, of direct relevance is the study of Blanchard et al. ${ }^{13}$ where very good agreement for the normal-to-axial force ratio is achieved between the measured Viking I data and the DSMC simulations of the Viking spacecraft at $11^{\circ}$ angle of incidence using the DAC code.

\section{RESULTS AND DISCUSSION}

Details of the hypersonic rarefied aerodynamics as calculated with DSMC analysis for Mars Pathfinder and Mars Microprobes follows. Figure 1 displays the configuration and relative size for both capsules.

\section{Mars Pathfinder}

The Pathfinder configuration and dimensions as used in the current calculations are given in Fig. 2 . The freestream conditions listed in Table 1 were generated for a nominal entry trajectory using a Clancey ${ }^{14}$ model for the atmosphere. As shown in Table 1, the atmospheric entry is initiated at $130.9 \mathrm{~km}$ with a relative velocity of $7.46 \mathrm{~km} / \mathrm{s}$. A higher altitude condition is included such that the flow is essentially free molecular. The degree of rarefaction is expressed in terms of the overall freestream Knudsen number defined herein as the ratio of the freestream, mean free path length, $\lambda_{\infty}$, to the maximum vehicle body diameter, $d$. Two values of Knudsen number are listed for the trajectory conditions: the VHS value, $\mathrm{Kn}_{\infty}$, normally quoted for DSMC simulations and a hard sphere, $\mathrm{Kn}_{\infty}, \mathrm{HS}$, value where a constant molecular diameter of $4.64 \times 10^{-10} \mathrm{~m}$ is used for $\mathrm{CO}_{2}$. The hard sphere Knudsen number values are reported since bridging relations used in trajectory analyses are often based on hard sphere values. Reynolds numbers, $R e_{\infty}$, are based on freestream viscosity evaluated with the VHS model for $\mathrm{CO}_{2}$ and a characteristic length equal to the body diameter, $d$.

Free Molecular Results Results for the free molecular aerodynamics are presented in Figs. 3 through 5 where the calculations were made using the DACFREE code. Freestream conditions are those for an altitude of $141.8 \mathrm{~km}$ and a wall temperature of $300 \mathrm{~K}$. Shown are the axial and normal force coefficients (Fig. 3), the center of pressure (Fig. 4) and the moment coefficient (Fig. 5) about the center of gravity (located $0.7154 \mathrm{~m}$ from the forebody nose) as a function of angle of incidence. The reference aerodynamic area and length are $\pi d^{2 / 4}$ and $d$, respectively. The center of pressure location (Fig. 4) 
is approximately constant until the angle of attack approaches the afterbody angle $\left(46.6^{\circ}\right)$. When this occurs, the afterbody conical frustrum is no longer fully shadowed by the forebody and the center of pressure location moves aft until an angle of attack of about $90^{\circ}$ is achieved. As $\alpha$ increases beyond $90^{\circ}$, the center of pressure moves forward as more of the afterbody sees the flow. At $133.4^{\circ}$, all the afterbody conical frustrum sees the flow and the center of pressure remains essentially constant for $\alpha$ up to $180^{\circ}$.

With Pathfinder's aft center of mass location (Fig. 4), it is statically unstable at free molecular conditions except in a backward position as it enters the Mars atmosphere. The modified Newtonian pitching moment results are also included in Fig. 5 where they were evaluated at freestream conditions corresponding to an altitude of $56.1 \mathrm{~km}$ (continuum flow) and with a ratio of specific heats equal $1.4\left(\mathrm{CO}_{2}\right.$ is a linear triatomic molecule). As evident in Fig. 5, Pathfinder goes from a statically unstable condition to a statically stable condition as it traverses the transitional flow regime. The impact on Pathfinder's entry attitude profile depends on how deep in the transitional flow regime the instability persists and the attitude control option exercised. As will be discussed later [see Fig. 14(c)], the static instability persists to an altitude of about $90 \mathrm{~km}$ where the zero incidence forces have increased from $0.09 \mathrm{~N}$ at $141.8 \mathrm{~km}$ to $93.7 \mathrm{~N}$ at $90.2 \mathrm{~km}(7027 \mathrm{~N}$ at $56.1 \mathrm{~km})$. Unlike the Viking 1 and 2 capsules which utilized an active control system throughout their entries, Mars Pathfinder will not rely on any form of active control (Ref. 2). Instead, an initial spin of two revolutions per minute and aerodynamic damping will be utilized to provide vehicle stability about a nominal zero degree trim angle throughout the entire atmospheric flight.

Impact of the transitional instability on Mars Pathfinder entry attitude profile is indicated in Fig. 6 where these results are from a recent six-degree-offreedom trajectory analysis provided by Braun (see Ref. 2 for a description of the method/procedure). Shown is the total angle of attack (square root of the sum of the squares of the angle of attack and the sidelip angles) as a function of time from $130.9 \mathrm{~km}$ altitude. The nominal entry assumes no error in the entry interface attitude. The trajectory simulation indicates that the gyroscopic effect of the vehicle spin is adequate for preventing unacceptable increase in vehicle attitude during the transitional portion of entry. As discussed in Refs. 1,2 and 15, two other small angle static instabilities exist in the continuum flow regime, one as the vehicle passes through peak heating and the other after peak dynamic pressure. Also, a supersonic dynamic instability region is evident before parachute deployment.

Axisymmetric calculations using G2 Calculations were made for all of the freestream conditions listed in Table 1 using the G2 DSMC code with the reacting chemistry model described earlier. For these calculations, the computational domain included only the Pathfinder forebody up to the maximum body diameter, location 3 in Fig. 2. A solution including the afterbody at $65 \mathrm{~km}$ altitude will be discussed later. Common to all the calculations was the subdivision of the forebody computational domain into four arbitrary regions and the use of 62 cells along the forebody surface. The size of the computational domain, the number of cell divisions normal to the surface, and the geometric progression of the cell size were adjusted with rarefaction to ensure that the cell size normal to the surface was less than the local mean free path length. Also, each cell was subdivided into 4 subcells. The number of molecules used in these simulations range from 76,000 to 290,000 .

Included in Table 2 are values for drag coefficient including both the total, $C_{D}$, and the pressure component of the drag, $C_{D, P}$, stagnation-point heat transfer coefficient $\left(C_{H}=2 q / \rho_{\infty} V_{\infty}^{3}\right.$ ) and stagnationpoint heating results. Figure 7 presents the drag coefficient as a function of hard-sphere Knudsen number, effectively the inverse of the freestream density since density is equal to a constant divided by $K n_{\infty, H S}$. Evident is the increase in the drag coefficient as the flow rarefaction increases from continuum to free molecular conditions, approaching the free molecular value of 2.072 for an assumed wall temperature of $300 \mathrm{~K}$. Note that free molecular conditions occur at an altitude higher than $142 \mathrm{~km}$ based on the drag coefficient results. For the range of conditions considered, the frictional drag component increases from 0.6 percent of the total drag at $K n_{\infty, H S}=0.001$ to 13.2 percent at a $K n_{\infty, H S}=100$. Also shown are results of two Navier Stokes (NS) solutions, again for only the forebody, obtained by Gnoffo $^{15}$ using the Langley Aerothermodynamic Upwind Relaxation Algorithm (LAURA) code. Agreement between the DSMC and NS solutions is very good. The calculations of Gnoffo show that the Pathfinder drag coefficient at $\alpha=0^{\circ}$ continues to increase in the hypersonic continuum regime until a value of $C_{D}=1.718$ is reached at a velocity of about $4.5 \mathrm{~km} / \mathrm{s}$. Figure 7 also includes results for modified Newtonian $(\gamma=1.4)$ and Newtonian (modified 
Newtonian with $\gamma=1.0$ ). For the smaller Knudsen number conditions the dissociation is substantial within the shock layer. Consequently, the use of an effective value for $\gamma$ to approximate the real gas effects in the shock layer would result in a value between 1.4 and 1.0. The modified Newtonian results with an appropriate effective $\gamma$ would be in closer agreement with the NS and DSMC results.

Knowing the drag coefficient, acceleration as a function of freestream density (or altitude) can be generated for an entry mass of $585.3 \mathrm{~kg}$ (assumed constant) and a cross-sectional area of $5.512 \mathrm{~m}^{2}$. For Mars Pathfinder, the calculated (Fig. 8) deceleration measured in Earth g's ranges from an order of $\mu \mathrm{g}$ 's to $1.0 \mathrm{~g}$ in the transitional flow regime. Peak values during entry are of the order of $20 \mathrm{~g}$ 's (Ref. 2).

Figures 9 through 12 present surface and flowfield results highlighting some of the aerothermal aspects of the high altitude portion of Pathfinder's entry. Both the stagnation-point heating rate and heating rate coefficient, $\mathrm{C}_{\mathrm{H}}$, values are listed in Table 2. Calculated heating rate distributions are presented in Fig. 9 for the three lowest altitudes considered where the wall temperature distributions are constant at the values listed in Table 2 . As the flow becomes less rarefied, the calculations show that the increase in heating rate at the outer shoulder expansion becomes more significant.

The level of dissociation is significant at the three lower altitude conditions. This is demonstrated in Fig. 10 where the $\mathrm{CO}_{2}$ mole fraction profiles along the stagnation stream line are presented. Depletion of $\mathrm{CO}_{2}$ within the shock layer is substantial, being complete for the lower altitude. Also evident in these results is the large change in shock layer thickness with rarefaction.

A calculation including both forebody and afterbody wake regions was also made for the $65 \mathrm{~km}$ altitude condition. The computational domain for the simulation was extended to a location $3.5 \mathrm{~m}$ downstream of the nose of Pathfinder. The computational domain was subdivided into 17 regions, 18,600 cells and 74,400 subcells. The number of particles in the simulation was 473,000 . Steady state was assumed to occur after 84,200 time steps and the simulation was continued to build up a large sample size for an additional 78,000 time steps. Results for the surface distributions for this case are presented in Fig. 11. The prescribed surface temperature was $1100 \mathrm{~K}$ up to the maximum surface radial location (location 3) and then ramped down to $450 \mathrm{~K}$ at an $\mathrm{s}$ location of 1.546 (just beyond location 5 in Fig. 11). The aerothermal loads along the afterbody are quite small compared to the forebody. For example, the maximum heating rate adjacent to location 3 has a value equal to 6.1 percent of the forebody stagnation point value. Along the afterbody base plane, the maximum heating is near location 6 , having a value of 2.1 percent of the forebody stagnation point value. The shear stress distribution is not shown along the forebody but rises from zero at the stagnation point to a nominal value of $6 \mathrm{~N} / \mathrm{m}^{2}$ along the forebody then rapidly increases to a maximum value of $20 \mathrm{~N} / \mathrm{m}^{2}$ at location 2. Along most of the afterbody $(s \geq$ 1.4330), the shear stress values are as shown in Fig. 11(b).

Shear stress reversal occurs at an $s$ location of $2.06 \mathrm{~m}(x=0.927 \mathrm{~m})$, with the initiation of a single vortex [Fig. 12(a)] that extends downstream of the afterbody to an $x$ location of $2.750 \mathrm{~m}$. Other aspects of the flowfield structure are evident in Fig. 12 where contours for density, overall kinetic temperature, pressure, and mole fractions for $\mathrm{CO}_{2}, \mathrm{CO}$, and atomic oxygen are presented. The depletion of $\mathrm{CO}_{2}$ in the forebody shock layer is almost complete near the surface [Fig. 12(e)] and the near wake flow consists predominantly of atomic oxygen and carbon monoxide with mole fractions of approximately 0.50 and 0.40 , respectively. If the surface had been catalytic, then the gas composition near the surface would have been different and the calculated heating rate values would have been higher.

The influence of the afterbody flow on the forebody results and drag for blunt body hypersonic rarefied flows at zero angle of attack have been consistently ${ }^{16-18}$ found to be insignificant. The same is true in the present study for the $65 \mathrm{~km}$ condition. For example, the drag calculated with the afterbody was 0.24 percent less than the solution that included only the forebody, a difference believed to be within the statistical scatter of the results.

Another observation found in related studies ${ }^{11,12}$ is that the blunt body aerodynamics for hypersonic rarefied flows are insensitive to whether the simulation is made with a reacting or nonreacting gas model. In the present study, calculations with a nonreacting, 2 species, and active rotational and vibrational gas model were conducted for altitudes of 85.1 and $65 \mathrm{~km}$. The ratios of the nonreacting to reacting drag coefficient for these cases were 1.0003 and 1.008, respectively, (see Fig. 13), again, a negligible effect. However, the nonreacting results are moderately sensitive to whether or not the $\mathrm{CO}_{2}$ vibrational modes are active. For the $65 \mathrm{~km}$ condition and nonreacting flow, the calculated drag coefficient with a vibrational relaxation collision number of 50 was 1.667 while that for a vibrational 
relaxation collision number of 5,000 was 1.581 , a 5.16 percent reduction when the participation of the four vibrational modes for $\mathrm{CO}_{2}$ is suppressed.

Three-dimensional calculations using_DAC The matrix of 3-D solutions that have been generated with DAC consisted of angles of attack of $0^{\circ}$ to $15^{\circ}$ in $5^{\circ}$ intervals and altitudes between 141.8 and $85.1 \mathrm{~km}$. This $15^{\circ}$ angle of attack envelope encompasses uncertainties associated with initial attitude errors ${ }^{2}$ and the static instability in the hypersonic transitional regime. The calculations were made for a nonreacting $\mathrm{CO}_{2} / \mathrm{N}_{2}$ gas model as described earlier. Results for axial, normal and moment coefficients are tabulated in Table 3. The tabulated moment coefficients, $C_{m o}$, are with respect to the nose of Pathfinder. The numerical simulations utilized the symmetry of the problem in that flow is computed about half of the capsule only. The forebody and near wake are included in the computational domain. At the more rarefied conditions only level-one cells are used in the simulations. For altitudes of $100 \mathrm{~km}$ and below, a minimum of two solutions were generated for each matrix point: a solution using a constant level-1 cell resolution throughout the computational domain and then at least one grid adaption was made to arrive at a new grid, where each level-1 cell has an independent refinement based on the local conditions within the level-1 cells. At $100 \mathrm{~km}$ altitude, the impact on the calculated results was about a 1.5 percent reduction in $C_{A}$. For the lower altitude conditions, the grid refinement produced a more significant reduction in each of the three aerodynamic coefficients and the results listed in Table 3 are based on the refined grid. The maximum number of particles used in the present 3-D simulations was 2.8 million.

When the DAC results for $C_{A}$ at $\alpha=0^{\circ}$ are compared with the G2 results (Fig. 13), the agreement is very good (better than 0.7 percent) except for the lowest altitude $(85.1 \mathrm{~km})$ DAC calculation. For the $85.1 \mathrm{~km}$ solution, the DAC result is higher by 1.8 percent than G2. This difference is believed to be due to the near surface coarse gridding implemented in the present DAC simulation (cell sizes for this $85.1 \mathrm{~km}$ solution were at best 2.5 times local mean free path along the forebody surface). Use of larger computational resources could resolve this question.

The comparisons shown in Fig. 13 support the previous observations that blunt body hypersonic rarefied aerodynamics are not influenced significantly by either afterbody or chemical reaction effects.

Figures 14(a) through 14(g) present the 3-D results for the aerodynamic coefficients as a function of angle of attack and rarefaction. The results show that the free molecular values using DACFREE are in excellent agreement with DAC when the collisions are deactivated (collisionless DSMC). Also, the magnitude of $K n_{\infty, \mathrm{HS}}$ is of the order of 100 or greater before free molecular conditions are achieved. These calculations show that Pathfinder becomes statically stable at small angles of attack for $K n_{\infty, H S}$ of the order 0.1 (altitude of approximately $90 \mathrm{~km}$ ). The aft movement of the center of pressure [Fig. 14(d)] is shown to be insensitive to the angle of attack variations considered. The lift is negative and quite small in comparison to the drag [Fig. 14(g)] for most of the transitional regime.

A goal of the Mars Pathfinder mission is to determine the performance of Pathfinder's entry, descent and landing systems, and reconstruct the Mars atmospheric structure at the time of entry. Density profile accuracy depends critically on $C_{D}$ knowledge. Data presented in Tables 2 and 3 are essential elements in the overall aerodynamic database that will be utilized in the postflight analyses.

\section{Mars Microprobes}

The computational codes and the general approach implemented in the numerical computations for the Mars Microprobe capsule are the same as that used for the Mars Pathfinder study. Both reacting and nonreacting calculations with active internal energy modes have been used. During the course of performing the computations, the baseline size of the Microprobe aeroshell was increased from an overall diameter of 0.325 to $0.350 \mathrm{~m}$. The axisymmetric calculations were made for the small configuration (see Table 4 for various dimensions) while the 3D simulations were made for the current baseline configuration shown in Fig. 15. The Microprobe geometry consists of a $45^{\circ}$ half angle spherically blunted forebody where the nose radius is equal to half the base radius. The transition from the forebody to afterbody is by means of an outer corner radius equal to five percent of the base radius. The afterbody is hemispherical in shape with the afterbody radius, $R_{a}$, centered at the center of gravity located $0.0839 \mathrm{~m}$ aft of the forebody stagnation point. A discussion of the mission requirements and constraints leading to this particular geometry is discussed in Ref. 4.

Since the Microprobes will encounter the Mars transitional flow region in a potentially tumbling mode, the manner in which they reorient themselves in a forward attitude and achieve a relatively small angle of attack will have important implications on the thermal protection system requirements (Ref. 19). 
This is particularly true for the small Microprobe capsules since heating rates will be quite high and the rarefied effects will persist to peak heating-rate conditions. Peak heating will occur near the lower altitude condition listed in Table 4.

Drag results from the axisymmetric G2 simulations both with and without reacting chemistry are included in Table 5 and are shown in Fig. 16. As expected, the change in the drag coefficient from continuum to free molecular conditions is much larger for the more slender Microprobe than the blunter Pathfinder: 86 percent for Microprobe versus 24 percent for Pathfinder. Also the contribution of friction to the total drag is significant: 7.4 percent at $K n_{\infty, \mathrm{HS}}=0.0017$ to 46 percent at $K n_{\infty, \mathrm{HS}}=80$. As was the case for Pathfinder, the drag at zero incidence is insensitive to whether the calculations are made with or without a reacting chemistry model. When the present results are compared (Fig. 16) with the NS calculations of Mitcheltree ${ }^{4}$, agreement is good for Knudsen numbers of the order of 0.001 . The NS results become questionable for Knudsen numbers larger than 0.05 . The NS drag results are bracketed by Newtonian and modified Newtonial values.

Free molecular results obtained with DACFREE are presented in Fig. 17. These calculations were made for freestream conditions corresponding to an altitude of $141.8 \mathrm{~km}$ (Table 6) and a wall temperature of $300 \mathrm{~K}$. Unlike Pathfinder, Microprobe is statically stable at free molecular conditions for $\alpha=0^{\circ}$ and unstable for a backwards attitude, a condition for which it was specifically designed as discussed by Mitcheltree, et al. ${ }^{4}$ In fact, the restoring moment coefficient becomes less as the probes descend into the continuum flow regime. The reduction in restoring moment is insignificant for angles of attack less than $25^{\circ}$ but very significant for larger angles of attack.

Results of the transitional aerodynamics calculated with DAC are listed in Table 7 for various angles of attack and three levels of rarefaction. The angle of attack ranges were selected to capture approximately 99 percent of the envelope of possible total angles-of-attack based on six-degree-of-freedom Monte Carlo trajectory simulations. Figure 18 displays the variation of $C_{A}, C_{N}, C_{m, c g}, x_{c p}, C_{L}, C_{D}$ and $L D$ for three levels of rarefaction as a function of angle of attack. The trends evident in the aerodynamic quantities presented in Fig. 18 are consistent with the free molecular and modified Newtonian data listed in Table 7. Mitcheltree, et al. ${ }^{4}$ discusses the use of bridging functions to achieve good agreement with the present Microprobe results.
The calculated heating rates are very much dependent on the thermochemical state of the shock layer. Stagnation-point heating results with and without reacting chemistry models for a noncatalytic wall are presented in Fig. 19. The reduction in surface heating due to shock layer nonequilibrium chemistry is about 8 percent at the $91.4 \mathrm{~km}$ altitude condition but increases to about 50 percent at the $54.9 \mathrm{~km}$ condition (Table 5). With the current chemistry modeling and the assumption of a noncatalytic surface, peak heating occurs between an altitude of 64 and $55 \mathrm{~km}$. Forebody surface heating rate distributions for the four lowest altitude conditions of Table 5 are shown in Fig. 20. Heating along the conical forebody is about half the stagnation point value. However, the heating rate distributions along the conical forebody are shown to be dependent on rarefaction. This is most apparent for the $54.9 \mathrm{~km}$ case where heating along the conical forebody increases, rather than continually decreases with distance, $s$, along the surface.

Trends evident in the heating rate distributions are also manifested in the corresponding surface pressure distributions presented in Fig. 21. The surface pressure has been normalized by the freestream dynamic pressure. The increase in the pressure coefficient on the spherical nose section with increasing rarefaction is qualitatively correct. On the conical frustrum, the pressure coefficient distribution is also seen to be influenced by rarefaction. For the smallest Knudsen number case considered, there is a substantial over expansion followed by recompression that influences the entire conical forebody, the qualitative behavior expected for this vehicle in hypersonic continuum flow. The process diminishes with increasing rarefaction. This behavior is identical to that observed in the calculations by Moss et al. ${ }^{7}$ for the Galileo Probe, also an entry capsule with a $45^{\circ}$ sperically blunted forebody.

The extent to which the surface is catalytic to the recombination of atomic oxygen and carbon monoxide will also influence the predicted heating since the concentration of these species adjacent to the surface is significant (Fig. 22) near peak heating conditions. The depletion of $\mathrm{CO}_{2}$, along the stagnation streamline (Fig. 23) is significant within the transitional flow regime, but not complete as was the case for Pathfinder. This occurs because the shock layer thickness is about an order of magnitude smaller than that for Pathfinder at comparable altitudes.

The observed increase in $\mathrm{CO}_{2}$ concentrations adjacent to a noncatalytic surface (Fig. 23) can be 
attributed to two potential effects. One is the chemical exchange reactions but not recombination reactions since they were omitted in the current chemistry model. The other possible contribution is that of thermal diffusion. Bird ${ }^{20}$ has shown that thermal diffusion for related hypersonic flows gives rise to an increase in heavy gas concentrations adjacent to surfaces. For large mass differences, thermal diffusion acts to concentrate the heavy gas in the cooler regions of the flow.

\section{CONCLUDING REMARKS}

Direct simulation Monte Carlo (DSMC) calculations complemented with free molecular and Newtonian solutions have been made for the Mars Pathfinder and Mars Microprobe capsules. The numerical simulations encompass representative direct entry conditions from free molecular to continuum hypersonic flows. Emphasis of the present study is the generation of transitional flow aerodynamic databases for both missions. For Pathfinder, the data is part of an overall database being used to update the sequence of events that will occur during entry and descent. Postflight analyses will rely on the axial and normal force coefficient data to extract atmospheric density from the accelerometer measurements during entry into the $\mathrm{CO}_{2} / \mathrm{N}_{2}$ atmosphere of Mars. For the Mars Microprobes, the database has been used to validate bridging relations for aerodynamic coefficients, which in turn are used in trajectory simulations to establish vehicle flyability. Computations for both Pathfinder and the Microprobes at zero incidence using an 8-species chemistry model provide information concerning heating and flowfield features.

Results of the computations show: 1) excellent agreement between free molecular and collisionless DSMC results; 2) excellent agreement between the axisymmetric and 3-D DSMC solutions for zero incidence; 3) excellent agreement between Navier Stokes and DSMC drag results for Knudsen numbers of the order of $0.001 ; 4$ ) that the aerodynamic drag for the current blunt body configurations at zero incidence are not influenced significantly by chemical reactions but are moderately sensitive to the vibrational modeling; and 5) a strong dependence of the flowfield structure and surface heating on the thermochemical state of the shock layer.

\section{ACKNOWLEDGMENTS}

The authors are indebted to $R$. D. Braun and R. A. Mitcheltree of the NASA Langley Research Center for providing trajectory information and entry conditions for Mars Pathfinder and Mars Microprobes along with discussions identifying the matrix of test conditions for the current study.

\section{REFERENCES}

${ }^{1}$ Spear, A. J., Freeman, Delma C., and Braun, Robert D., "Mars Pathfinder Status at Launch," IAF-96Q.3.02 47th International Astronautical Congress, Oct. 1996.

2Braun, Robert D., Powell, Richard W., Engelund, Walter C., Gnoffo, Peter A., Weilmuenster, K. James, and Mitcheltree, Robert A., "Mars Pathfinder Six-Degrees-of-Freedom Entry Analysis," Journal of Spacecraft and Rockets, Vol. 32, No. 6, Nov-Dec 1995, pp. 993-1000.

${ }^{3}$ Bird, G. A., "Molecular Gas Dynamics and the Direct Simulation of Gas Flows," Clarendon Press, Oxford, 1994.

${ }^{4}$ Mitcheltree, R. A., Moss, J. N., Cheatwood, F. M., Green, F. A., and Braun, R. D., "Aerodynamics of the Mars Microprobe Entry Vehicles," AIAA Paper 97-3658, August 1997.

5Bird, G. A., "The G2/A3 Program Users Manual." G. A. B. Consulting Pty Ltd, Killara, N.S.W., Australia, March 1992.

${ }^{6}$ Wilmoth, R. G., LeBeau, G. J., and Carlson, A. B., "DSMC Grid Methodologies for Computing LowDensity Hypersonic Flows about Reusable Launch Vehicles," AIAA Paper 96-1812, June 1996.

${ }^{7}$ Moss, James N., LeBeau, Gerald J., Blanchard, Robert C., and Price, Joseph M., "Rarefaction Effects on Galileo Probe Aerodynamics," 20th International Symposium of Rarefied Gas Dynamics, Beijing, China, August 1996.

${ }^{8}$ Anderson, J. D., Jr., "Hypersonic and High Temperature Gas Dynamics," McGraw-Hill Book Company, 1989.

${ }^{9}$ Borgnakke, C. and Larsen, P.S., "Statistical Collision Model for Monte Carlo Simulation of 
Polyatomic Gas Mixture," Journal of Computational Physics, Vol. 18, No. 4, 1975, pp. 405-420.

${ }^{10}$ Hash, David B. and Hassan, H. A., "Monte Carlo Simulation of Entry in the Martian Atmosphere," Journal of Thermophysics and Heat Transfer, Vol., 7, No. 2, April-June 1993, pp. 228-232.

${ }^{11}$ Anon, "Hypersonic Experimental and Computational Capabilities: Improvement and Validation," AGARD AR-319, Vol. 2, To be published in 1997.

12Moss, J. N. and Price, J. M., "Survey of Blunt Body Flows Including Wakes at Hypersonic LowDensity Conditions," Journal of Thermophysics and Heat Transfer, Vol. 11, No. 3, July-Sept 1997.

${ }^{13}$ Blanchard, R. C., Wilmoth, R. G., and Moss, J. N., "Aerodynamic Flight Measurements and DSMC Simulation of Blunt Body Mars Entry Vehicles," Journal of Spacecraft and Rockets, Accepted for publication.

${ }^{14}$ Clancy, R. T., Lee, S. W., Gladstone, G. R., McMillan, W. W., and Rousch, T., "A New Model of Mars Atmospheric Dust Based on Analysis of Ultraviolet Through Infrared Observations for Mariner-9, Viking and Phobos," Journal of Geophysical Research, Vol. 100, 1995, pp. 5251-5263.
${ }^{15}$ Gnoffo, P. A., Weilmuenster, K. J., Braun, R. D., and Cruz, C. I., "Influence of Sonic-Line Location on Mars Pathfinder Probe Aerodynamics," Journal of Spacecraft and Rockets, Vol. 33, No. 2, MarchApril 1996, pp. 169-177.

16Moss, J. N., Dogra, V. K., and Wilmoth, R. G., "DSMC Simulations of Mach 20 Nitrogen Flows About A $70^{\circ}$ Blunted Cone and Its Wake," NASA TM 107762, August 1993.

${ }^{17}$ Celenligil, M. C., Moss, J. N. and Blanchard, R. C., "Three-Dimensional Rarefied Flow Simulations for the Aeroassist Flight Experiment Vehicle," AIAA Journal, Vol. 29, No. 1, January 1991, pp. 52-57.

${ }^{18}$ Wilmoth, R. G., Mitcheltree, R. A., Moss, J. N. and Dogra, V. K., "Zonally Decoupled Direct Simulation Monte Carlo Simulations of Hypersonic Blunt-Body Wake Flows," Journal of Spacecraft and Rockets, Vol. 31, No. 6, Nov.-Dec. 1994, pp. 971-979.

${ }^{19}$ Mitcheltree, R. A., DiFulvio, M., Horvath, T. J., and Braun, R. D., "Aerothermal Heating Predictions for Mars Microprobe," Proposed AIAA Paper, January 1998.

${ }^{20}$ Bird, G. A., "Thermal and Pressure Diffusion Effects in High Altitude Flows," AIAA Paper 88-2732, June 1988. 
Table 1. Freestream and surface conditions ${ }^{a}$ for Mars Pathfinder nominal entry trajectory

\begin{tabular}{rrrccccr}
\hline $\begin{array}{c}\text { Altitude, } \\
\mathbf{k m}\end{array}$ & $\begin{array}{c}\text { Time, } \\
\mathrm{s}\end{array}$ & $\begin{array}{c}\mathrm{V}_{\infty}, \\
\mathrm{m} / \mathrm{s}\end{array}$ & $\begin{array}{c}\rho_{\infty}, \\
\mathrm{kg} / \mathrm{m}^{3}\end{array}$ & $\begin{array}{c}\mathrm{T}_{\mathrm{w}}^{\mathrm{b}}, \\
\mathrm{K}\end{array}$ & $\mathrm{Kn}_{\infty}$ & $\mathrm{Kn}_{\infty, \mathrm{HS}}$ & $\mathrm{Re}_{\infty}$ \\
\hline 141.8 & - & $7,463.1$ & $2.8351 \times 10^{-10}$ & 300 & $5.50 \times 10^{1}$ & $1.00 \times 10^{2}$ & 1 \\
130.9 & 0.0 & $7,463.1$ & $1.1767 \times 10^{-9}$ & 389 & $1.32 \times 10^{1}$ & $2.41 \times 10^{1}$ & 3 \\
119.0 & 6.8 & $7,468.6$ & $5.6344 \times 10^{-9}$ & 470 & $2.76 \times 10^{0}$ & $5.03 \times 10^{0}$ & 16 \\
110.1 & 12.1 & $7,472.8$ & $1.8386 \times 10^{-8}$ & 560 & $8.47 \times 10^{-1}$ & $1.54 \times 10^{0}$ & 52 \\
100.0 & 18.3 & $7,477.3$ & $7.0212 \times 10^{-8}$ & 675 & $2.22 \times 10^{-1}$ & $4.04 \times 10^{-1}$ & 199 \\
95.0 & 21.5 & $7,479.5$ & $1.3759 \times 10^{-7}$ & 750 & $1.13 \times 10^{-1}$ & $2.06 \times 10^{-1}$ & 390 \\
90.2 & 24.6 & $7,481.5$ & $2.6074 \times 10^{-7}$ & 824 & $5.98 \times 10^{-2}$ & $1.09 \times 10^{-1}$ & 740 \\
85.1 & 28.0 & $7,483.3$ & $5.1816 \times 10^{-7}$ & 900 & $3.01 \times 10^{-2}$ & $5.47 \times 10^{-2}$ & 1,471 \\
80.0 & 31.5 & $7,484.6$ & $1.0342 \times 10^{-6}$ & 950 & $1.15 \times 10^{-2}$ & $2.71 \times 10^{-2}$ & 2,936 \\
75.0 & 35.0 & $7,484.6$ & $2.0301 \times 10^{-6}$ & 1000 & $7.67 \times 10^{-3}$ & $1.40 \times 10^{-2}$ & 5,763 \\
65.0 & 42.3 & $7,453.9$ & $7.9450 \times 10^{-6}$ & 1100 & $1.96 \times 10^{-3}$ & $3.57 \times 10^{-3}$ & 22,460 \\
56.1 & 49.3 & $7,431.3$ & $2.7614 \times 10^{-5}$ & 1500 & $5.60 \times 10^{-4}$ & $1.03 \times 10^{-3}$ & 77,940 \\
\hline \hline
\end{tabular}

Table 2. Mars Pathfinder aerodynamic and heating results for zero incidence

\begin{tabular}{ccccc}
\hline \hline $\begin{array}{c}\text { Altitude, } \\
\mathrm{km}\end{array}$ & $\mathrm{C}_{\mathrm{D}}$ & $\mathrm{C}_{\mathrm{D}, \mathrm{P}}$ & \multicolumn{2}{c}{ Stagnation-Point } \\
\cline { 4 - 5 } & & & $\mathrm{C}_{\mathrm{H}}$ & $\mathrm{q}, \mathrm{W} / \mathrm{cm}^{2}$ \\
\hline 141.8 & 2.066 & 1.793 & 1.000 & $5.918 \times 10^{-3}$ \\
130.9 & 2.059 & 1.790 & 0.981 & $2.398 \times 10^{-2}$ \\
119.0 & 2.014 & 1.755 & 0.945 & $1.109 \times 10^{-1}$ \\
110.1 & 1.972 & 1.731 & 0.861 & $3.302 \times 10^{-1}$ \\
100.0 & 1.921 & 1.721 & 0.788 & $1.156 \times 10^{0}$ \\
95.0 & 1.872 & 1.704 & 0.714 & $2.056 \times 10^{0}$ \\
90.2 & 1.832 & 1.700 & 0.652 & $3.558 \times 10^{0}$ \\
85.1 & 1.746 & 1.657 & 0.544 & $5.904 \times 10^{0}$ \\
80.0 & 1.688 & 1.630 & 0.393 & $8.518 \times 10^{0}$ \\
75.0 & 1.655 & 1.617 & 0.261 & $1.111 \times 10^{1}$ \\
65.0 & 1.654 & 1.635 & 0.097 & $1.592 \times 10^{1}$ \\
56.1 & 1.672 & 1.662 & 0.035 & $2.002 \times 10^{1}$ \\
\hline \hline
\end{tabular}


Table 3. Mars Pathfinder aerodynamics for $0^{\circ}$ to $15^{\circ}$ incidence

\begin{tabular}{|c|c|c|c|}
\hline $\begin{array}{c}\text { Angle of } \\
\text { attack, deg }\end{array}$ & $\mathrm{C}_{\mathrm{A}}$ & $\mathrm{C}_{\mathrm{N}}$ & $\mathrm{C}_{\mathrm{m}, \mathrm{o}}$ \\
\hline Altitude $=141.8 \mathrm{~km}$ & Free molecular & & \\
\hline 0 & 2.072 & 0.0 & 0.0 \\
\hline 5 & 2.057 & 0.174 & -0.0321 \\
\hline 10 & 2.011 & 0.343 & -0.0631 \\
\hline 15 & 1.939 & 0.502 & -0.0922 \\
\hline Altitude $=141.8 \mathrm{~km}$ & Collisionless DAC & & \\
\hline 0 & 2.073 & 0.0 & 0.0 \\
\hline 5 & 2.057 & 0.174 & -0.0323 \\
\hline 10 & 2.012 & 0.343 & -0.0637 \\
\hline 15 & 1.939 & 0.502 & -0.0926 \\
\hline Altitude $=141.8 \mathrm{~km}$ & DAC & & \\
\hline 0 & 2.063 & 0.0 & 0.0 \\
\hline 5 & 2.049 & 0.172 & -0.0318 \\
\hline 10 & 2.005 & 0.340 & -0.0633 \\
\hline 15 & 1.931 & 0.498 & -0.0923 \\
\hline Altitude $=130.9 \mathrm{~km}$ & DAC & & \\
\hline 0 & 2.055 & 0.0 & 0.0 \\
\hline 5 & 2.040 & 0.169 & -0.0319 \\
\hline 10 & 1.996 & 0.334 & -0.0631 \\
\hline 15 & 1.926 & 0.488 & -0.0923 \\
\hline Altitude $=119.0 \mathrm{~km}$ & DAC & & \\
\hline 0 & 2.000 & 0.0 & 0.0 \\
\hline 5 & 1.987 & 0.158 & -0.0307 \\
\hline 10 & 1.944 & 0.310 & -0.0608 \\
\hline 15 & 1.878 & 0.455 & -0.0892 \\
\hline Altitude $=110.1 \mathrm{~km}$ & DAC & & \\
\hline 0 & 1.969 & 0.0 & 0.0 \\
\hline 5 & 1.954 & 0.144 & -0.0296 \\
\hline 10 & 1.914 & 0.284 & -0.0584 \\
\hline 15 & 1.842 & 0.415 & -0.0855 \\
\hline Altitude $=100.0 \mathrm{~km}$ & DAC & & \\
\hline 0 & 1.931 & 0.0 & 0.0 \\
\hline 5 & 1.919 & 0.122 & -0.0269 \\
\hline 10 & 1.882 & 0.240 & -0.0544 \\
\hline 15 & 1.812 & 0.351 & -0.0794 \\
\hline Altitude $=95.0 \mathrm{~km}$ & DAC & & \\
\hline 0 & 1.883 & 0.0 & 0.0 \\
\hline 5 & 1.866 & 0.104 & -0.0254 \\
\hline 10 & 1.830 & 0.207 & -0.0519 \\
\hline 15 & 1.771 & 0.304 & -0.0763 \\
\hline
\end{tabular}


Table 3. Continued

\begin{tabular}{cccc}
\hline $\begin{array}{c}\text { Angle of } \\
\text { attack, deg }\end{array}$ & $\mathrm{C}_{\mathrm{A}}$ & $\mathrm{C}_{\mathrm{N}}$ & $\mathrm{C}_{\mathrm{m}, 0}$ \\
\hline Altitude $=90.2 \mathrm{~km}$ & DAC & & \\
\hline 0 & 1.831 & 0.0 & 0.0 \\
5 & 1.815 & 0.087 & -0.0240 \\
10 & 1.781 & 0.176 & -0.0493 \\
15 & 1.726 & 0.259 & -0.0721 \\
\hline Altitude $=85.1 \mathrm{~km}$ & DAC & & 0.0 \\
\hline 0 & 1.778 & 0.0 & -0.0215 \\
5 & 1.767 & 0.070 & -0.0425 \\
10 & 1.732 & 0.137 & -0.0644 \\
15 & 1.672 & 0.205 & \\
\hline Altitude $=56.1 \mathrm{~km}$ & Modified Newtonian $(\gamma=1.4)$ & 0.0 \\
\hline 0 & 1.583 & 0.0 & -0.0200 \\
5 & 1.572 & 0.022 & -0.0394 \\
10 & 1.539 & 0.043 & -0.0577 \\
15 & 1.485 & 0.064 & \\
\hline \hline
\end{tabular}

Table 4. Freestream ${ }^{a}$ and surface conditions for Mars Microprobe ${ }^{b}$ overshoot trajectory

\begin{tabular}{rcccccrr}
\hline $\begin{array}{c}\text { Altitude, } \\
\mathrm{km}\end{array}$ & $\begin{array}{c}\mathrm{V}_{\infty}, \\
\mathrm{m} / \mathrm{s}\end{array}$ & $\begin{array}{c}\rho_{\infty}, \\
\mathrm{kg} / \mathrm{m}^{3}\end{array}$ & $\begin{array}{c}\mathrm{T}_{\infty}, \\
\mathrm{K}\end{array}$ & $\begin{array}{c}\mathrm{T}_{\mathrm{w}}{ }^{\mathrm{c}}, \\
\mathrm{K}\end{array}$ & $\mathrm{Kn}_{\infty}$ & $\mathrm{Kn}_{\infty, \mathrm{HS}}$ & $\mathrm{Re}_{\infty}$ \\
\hline 126.72 & 6,909 & $2.6891 \times 10^{-9}$ & 171.4 & 300 & 50.5365 & 79.8036 & 1 \\
113.20 & 6,916 & $2.3065 \times 10^{-8}$ & 154.5 & 400 & 5.7077 & 9.3040 & 7 \\
98.69 & 6,922 & $2.3169 \times 10^{-7}$ & 136.3 & 500 & 0.5468 & 0.9262 & 75 \\
91.41 & 6,923 & $7.6309 \times 10^{-7}$ & 124.6 & 600 & 0.1615 & 0.2812 & 266 \\
80.47 & 6,913 & $3.8356 \times 10^{-6}$ & 133.8 & 900 & 0.0328 & 0.0560 & 1,261 \\
73.42 & 6,884 & $9.4629 \times 10^{-6}$ & 146.4 & 1,200 & 0.0137 & 0.0268 & 2,879 \\
64.29 & 6,751 & $3.4315 \times 10^{-5}$ & 143.1 & 1,500 & 0.0038 & 0.0063 & 10,430 \\
54.88 & 6,168 & $1.2709 \times 10^{-4}$ & 149.9 & 1,800 & 0.0010 & 0.0017 & 34,000 \\
\hline
\end{tabular}

a Freestream mole fractions are $\mathrm{X}_{\mathrm{CO}_{2}}=0.95366$ and $\mathrm{X}_{\mathrm{N}_{2}}=0.04634$; Molecular weight $=43.2685$; and diffuse surface with full thermal accommodation.

${ }^{b}$ Probe diameter $=0.325 \mathrm{~m}, \mathrm{R}_{\mathrm{n}}=0.08125 \mathrm{~m}$ and $\mathrm{R}_{\mathrm{c}}=0.008125 \mathrm{~m}$.

'Assumed wall temperature values. 
Table 5. Mars Microprobe aerodynamic and heating results for overshoot trajectory and zero incidence

\begin{tabular}{|c|c|c|c|c|c|c|}
\hline \multirow[b]{2}{*}{ Altitude, $\mathrm{km}$} & \multicolumn{2}{|c|}{$C_{D, P}$} & \multicolumn{2}{|c|}{$\mathrm{C}_{\mathrm{D}}$} & \multicolumn{2}{|c|}{ Stagnation-Point $\mathrm{q}, \mathrm{W} / \mathrm{cm}^{2}$} \\
\hline & N.R. ${ }^{\mathbf{a}}$ & $\overrightarrow{\text { Reacting }} \mathrm{b}$ & N.R. & Reacting & N.R. & Reacting \\
\hline 126.72 & 1.109 & & 2.053 & & 0.04 & \\
\hline 113.20 & 1.107 & & 2.010 & & 0.37 & \\
\hline 98.69 & 1.105 & & 1.868 & & 3.58 & \\
\hline 91.41 & 1.125 & 1.118 & 1.771 & 1.776 & 11.0 & 10.1 \\
\hline 80.47 & 1.105 & 1.097 & 1.522 & 1.518 & 44.2 & 38.9 \\
\hline 73.42 & 1.060 & 1.058 & 1.352 & 1.343 & 85.5 & 71.5 \\
\hline 64.29 & 1.024 & 1.028 & 1.190 & 1.176 & 177.1 & 118.3 \\
\hline 54.88 & 1.023 & 1.023 & 1.097 & 1.087 & 216.3 & 110.3 \\
\hline
\end{tabular}

${ }^{2}$ Nonreacting flow results

beacting flow results

Table 6. Flight conditions ${ }^{\mathrm{a}}$ for Mars Microprobe ${ }^{\mathrm{b}}$ nominal trajectory.

\begin{tabular}{cccccc}
\hline \hline $\begin{array}{c}\text { Altitude, } \\
\mathrm{km}\end{array}$ & $\begin{array}{c}\mathrm{V}_{\infty}, \\
\mathrm{m} / \mathrm{s}\end{array}$ & $\begin{array}{c}\rho_{\infty}, \\
\mathrm{kg} / \mathrm{m}^{3}\end{array}$ & $\begin{array}{c}\mathrm{T}_{\infty}, \\
\mathrm{k}\end{array}$ & $\begin{array}{c}\mathrm{T}_{\mathrm{w}}, \mathrm{c} \\
\mathrm{k}\end{array}$ & $\mathrm{Kn}_{\infty, \mathrm{HS}}$ \\
\hline 141.80 & 6,902 & $2.4438 \times 10^{-10}$ & 190.2 & 300 & $8.78 \times 10^{2}$ \\
126.69 & 6,909 & $2.1000 \times 10^{-9}$ & 171.3 & 300 & $7.95 \times 10^{1}$ \\
100.61 & 6,921 & $1.7066 \times 10^{-7}$ & 138.7 & 500 & $1.26 \times 10^{0}$ \\
80.28 & 6,908 & $3.9287 \times 10^{-6}$ & 134.3 & 900 & $5.46 \times 10^{-2}$ \\
53.84 & 6,090 & $1.4105 \times 10^{-4}$ & 154.5 & 2000 & $1.52 \times 10^{-3}$ \\
\hline \hline
\end{tabular}

${ }^{2}$ Freestream mole fractions are $\mathrm{X}_{\mathrm{CO}_{2}}=0.95366$ and $\mathrm{X}_{\mathrm{N}_{2}}=0.04634$; Molecular weight $=43.2685$; and diffuse surface with full thermal accommodation.

brobe diameter $=0.350 \mathrm{~m}, \mathrm{R}_{\mathrm{n}}=0.0875 \mathrm{~m}$ and $\mathrm{R}_{\mathrm{c}}=0.00875 \mathrm{~m}$.

${ }^{c}$ Assumed wall temperature values. 
Table 7. Mars Microprobe aerodynamics for nominal trajectory

\begin{tabular}{|c|c|c|c|}
\hline $\begin{array}{l}\text { Angle of } \\
\text { attack, deg }\end{array}$ & $\mathrm{C}_{\mathrm{A}}$ & $\mathrm{C}_{\mathrm{N}}$ & $\mathrm{C}_{\mathrm{m}, \mathrm{o}}$ \\
\hline Altitude $=141.80 \mathrm{~km}$ & Free Molecular & & \\
\hline $\begin{array}{c}0 \\
5 \\
15 \\
30 \\
45 \\
60 \\
75 \\
90 \\
105 \\
120 \\
135 \\
150 \\
165 \\
180 \\
\end{array}$ & $\begin{array}{c}2.061 \\
2.046 \\
1.928 \\
1.574 \\
1.120 \\
0.724 \\
0.360 \\
0.0014 \\
-0.358 \\
-0.725 \\
-1.123 \\
-1.574 \\
-1.928 \\
-2.061 \\
\end{array}$ & $\begin{array}{l}0.000 \\
0.176 \\
0.508 \\
0.893 \\
1.100 \\
1.229 \\
1.311 \\
1.338 \\
1.310 \\
1.227 \\
1.098 \\
0.894 \\
0.509 \\
0.000 \\
\end{array}$ & $\begin{array}{l}.0000 \\
-.0721 \\
-.2081 \\
-.3703 \\
-.4769 \\
-.5235 \\
-.5429 \\
-.5472 \\
-.5394 \\
-.5169 \\
-.4692 \\
-.3654 \\
-.2056 \\
.0000 \\
\end{array}$ \\
\hline Altitude $=126.69 \mathrm{~km}$ & DAC & & \\
\hline $\begin{array}{c}0 \\
5 \\
15 \\
30 \\
45 \\
60 \\
75 \\
90 \\
105 \\
120 \\
135 \\
150 \\
165 \\
180 \\
\end{array}$ & $\begin{array}{l}2.054 \\
2.040 \\
1.921 \\
1.574 \\
1.118 \\
0.723 \\
0.360 \\
0.0015 \\
-0.358 \\
-0.725 \\
-1.122 \\
-1.570 \\
-1.921 \\
-2.054 \\
\end{array}$ & $\begin{array}{l}0.000 \\
0.176 \\
0.505 \\
0.891 \\
1.097 \\
1.225 \\
1.306 \\
1.336 \\
1.305 \\
1.224 \\
1.095 \\
0.890 \\
0.506 \\
0.000 \\
\end{array}$ & $\begin{array}{r}.0001 \\
-.0718 \\
-.2061 \\
-.3700 \\
-.4755 \\
-.5593 \\
-.5413 \\
-.5469 \\
-.5370 \\
-.5152 \\
-.4672 \\
-.3626 \\
-.2040 \\
.0002 \\
\end{array}$ \\
\hline Altitude $=100.61 \mathrm{~km}$ & DAC & & \\
\hline $\begin{array}{c}0 \\
5 \\
15 \\
30 \\
45 \\
60 \\
75 \\
90\end{array}$ & $\begin{array}{l}.901 \\
1.891 \\
1.788 \\
1.470 \\
1.071 \\
0.716 \\
0.369 \\
0.0008\end{array}$ & $\begin{array}{l}0.000 \\
0.156 \\
0.452 \\
0.794 \\
0.991 \\
1.126 \\
1.222 \\
1.252\end{array}$ & $\begin{array}{l}-.0004 \\
-.0657 \\
-.1910 \\
-.3403 \\
-.4391 \\
-.4911 \\
-.5161 \\
-.5138\end{array}$ \\
\hline
\end{tabular}


Table 7. Continued.

\begin{tabular}{cccc}
\hline Altitude $=80.28 \mathrm{~km}$ & \multicolumn{1}{l}{ DAC } & \\
\hline 0 & 1.536 & 0.001 & -.0013 \\
5 & 1.520 & 0.128 & -.0580 \\
15 & 1.424 & 0.360 & -.1650 \\
30 & 1.180 & 0.607 & -.2838 \\
45 & 0.904 & 0.734 & -.3525 \\
60 & 0.656 & 0.846 & -.4035 \\
\hline Altitude $=53.84 \mathrm{~km}$ & Modified Newtonian $(\gamma=1.4)$ & \\
\hline 0 & 0.962 & .0000 \\
5 & 0.958 & 0.000 & -.0450 \\
15 & 0.926 & 0.076 & -.1298 \\
30 & 0.830 & 0.219 & -.2260 \\
45 & 0.690 & 0.382 & -.2668 \\
60 & 0.511 & -.2564 \\
75 & 0.279 & 0.461 & -.2215 \\
90 & 0.013 & 0.472 & -.1787 \\
105 & -0.259 & 0.460 & -.1414 \\
120 & -0.504 & 0.449 & -.1177 \\
135 & -0.703 & 0.447 & -.1065 \\
150 & -0.862 & 0.449 & -.0872 \\
165 & -0.973 & 0.436 & -.0497 \\
180 & -0.101 & 0.360 & .0000 \\
\hline
\end{tabular}




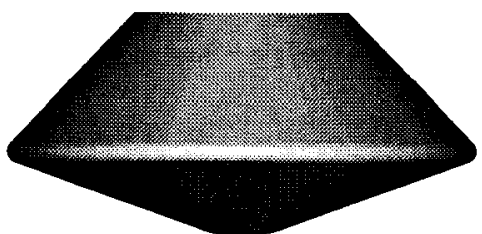

Mars Pathfinder

$70.19^{\circ}$ forebody $/ 46.63^{\circ}$ afterbody, $d=2.65 \mathrm{~m}$

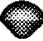

Mars Microprobe

$45^{\circ}$ forebody/hemispherical afterbody, $d=0.35 \mathrm{~m}$

Fig. 1 Capsule configurations and relative size.

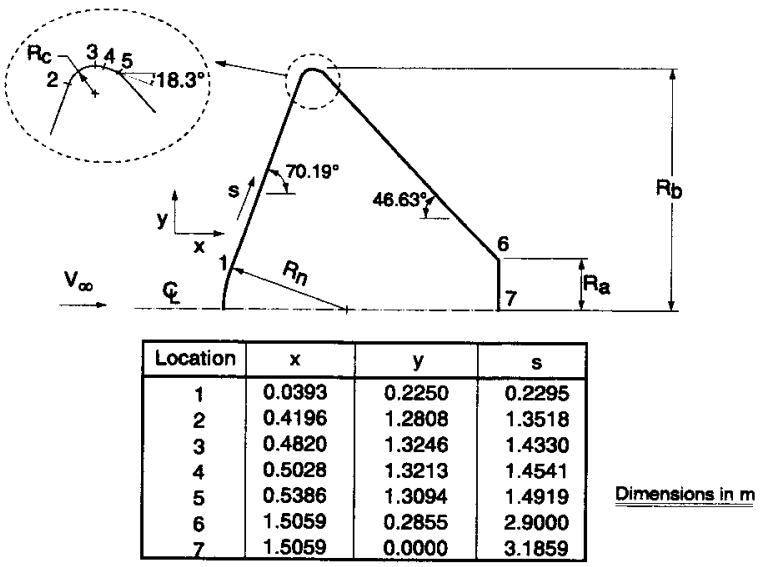

Fig. 2 Mars Pathfinder configuration $\left(R_{n}=0.6638\right.$, $R_{c}=0.0662, R_{a}=0.2855$ and $R_{b}=1.3246$ )

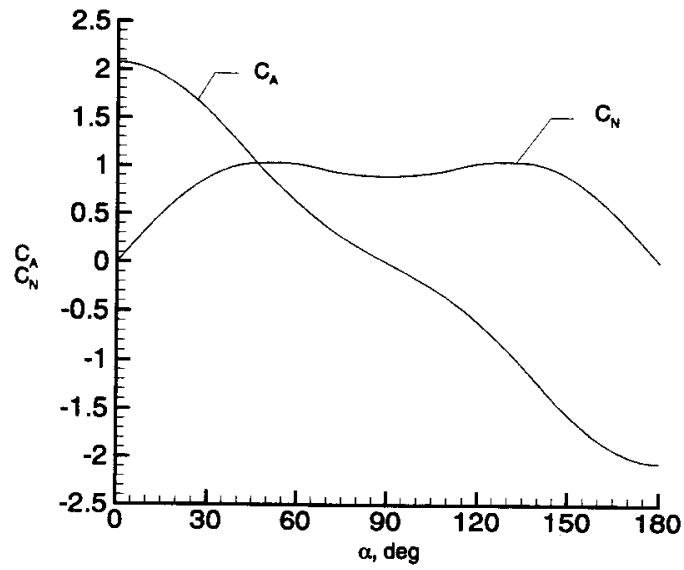

Fig. 3 Pathfinder free molecular aerodynamic axial and normal force coefficients as a function of angle of attack.

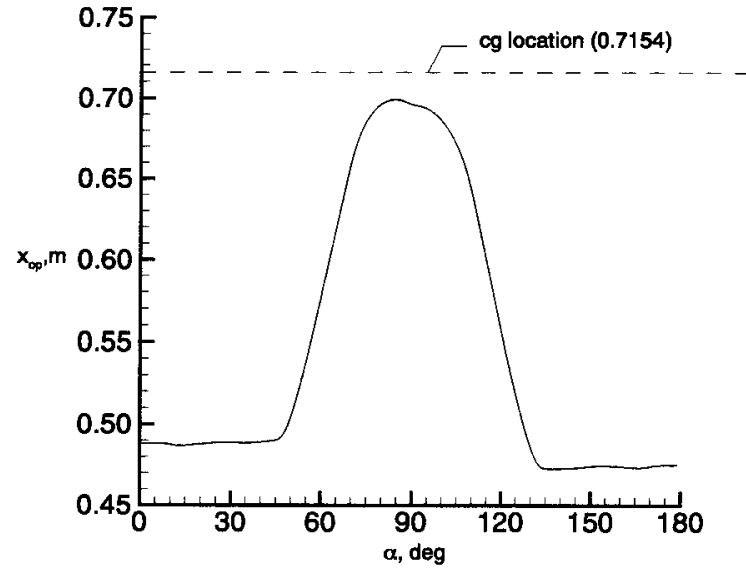

Fig. 4 Pathfinder free molecular center of pressure location as a function of angle of attack.

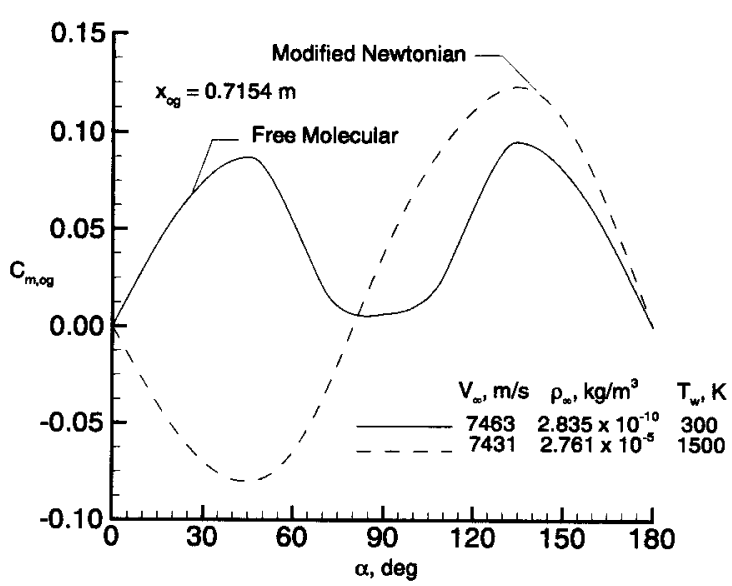

Fig. 5 Pathfinder pitching moment coefficient computed using free molecular and modified Newtonian $(\gamma=1.4)$ relations as a function of angle of attack.

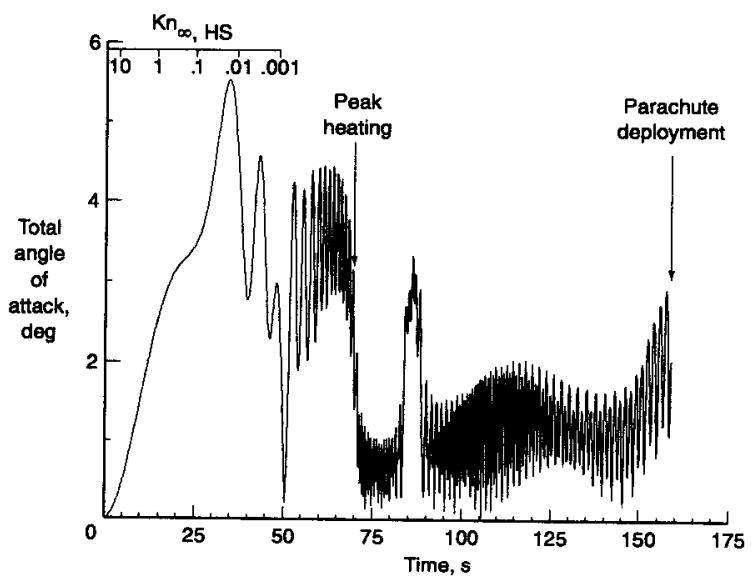

Fig. 6 Nominal six-degree-of-freedom Mars Pathfinder entry attitude profile. 


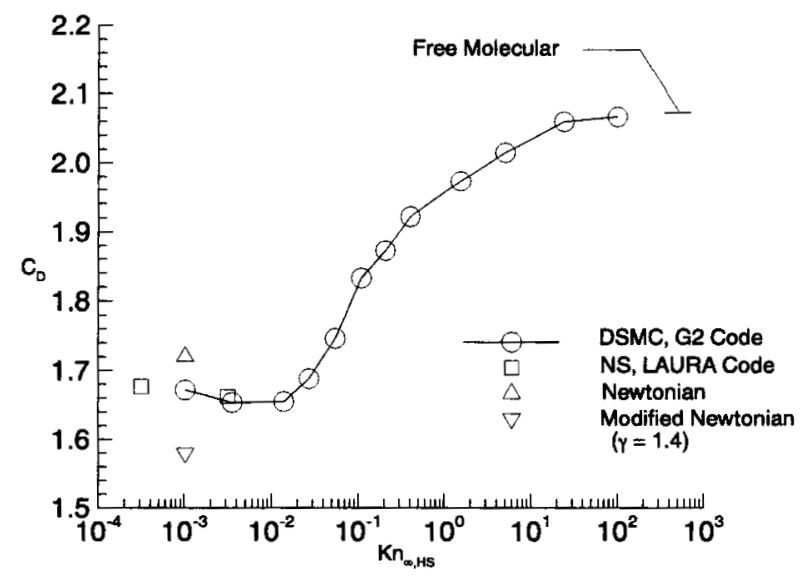

Fig. 7 Pathfinder darg coefficient for $\alpha=0^{\circ}$.

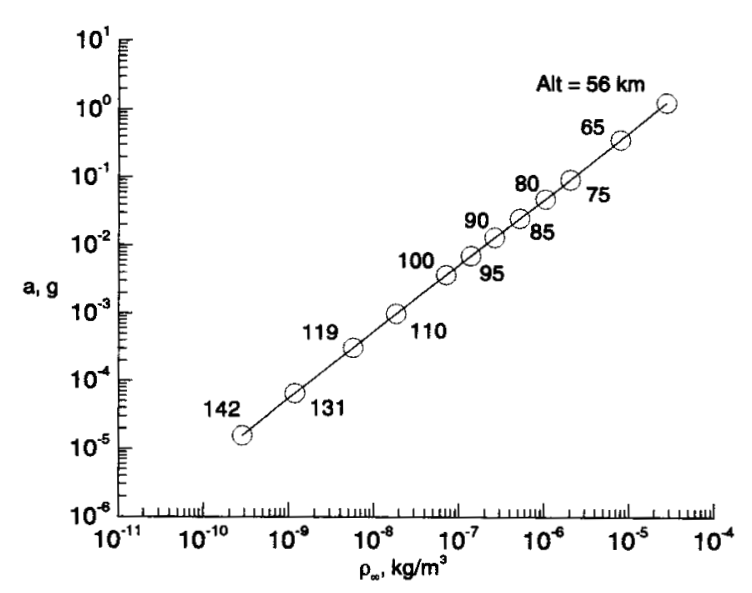

Fig. 8 Pathfinder calculated deceleration during the high altitude portion of entry.

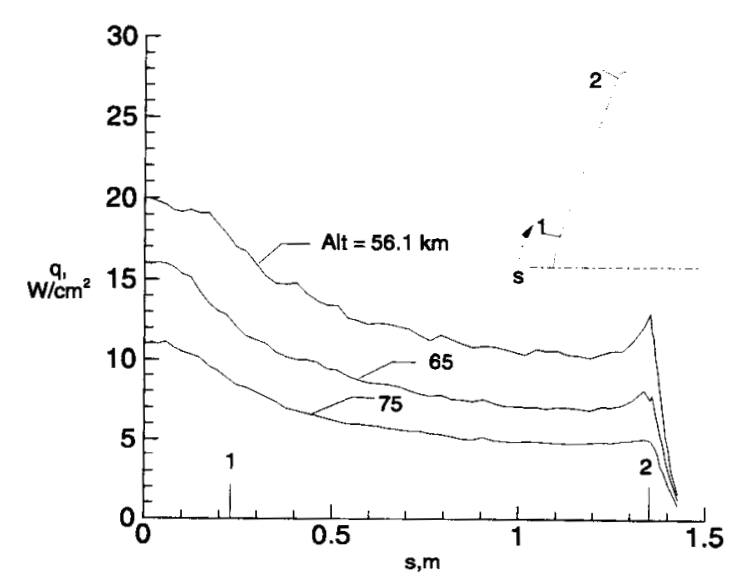

Fig. 9 Pathfinder forebody heating rate distributions.

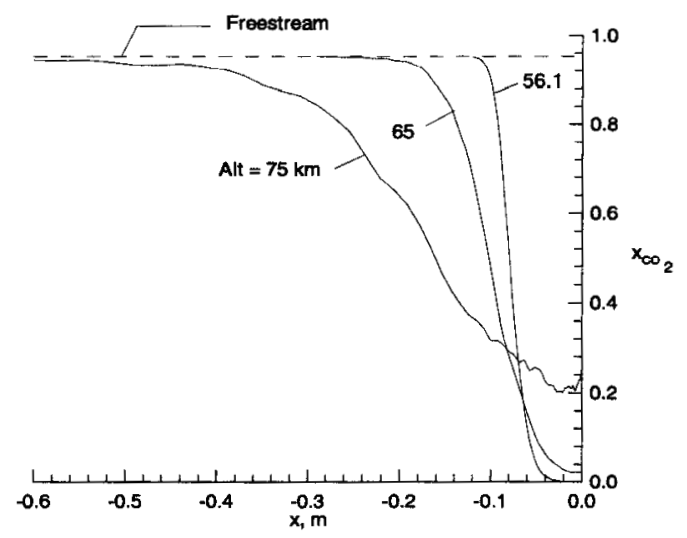

Fig. $10 \mathrm{CO}_{2}$ mole fraction profiles along stagnation streamline.

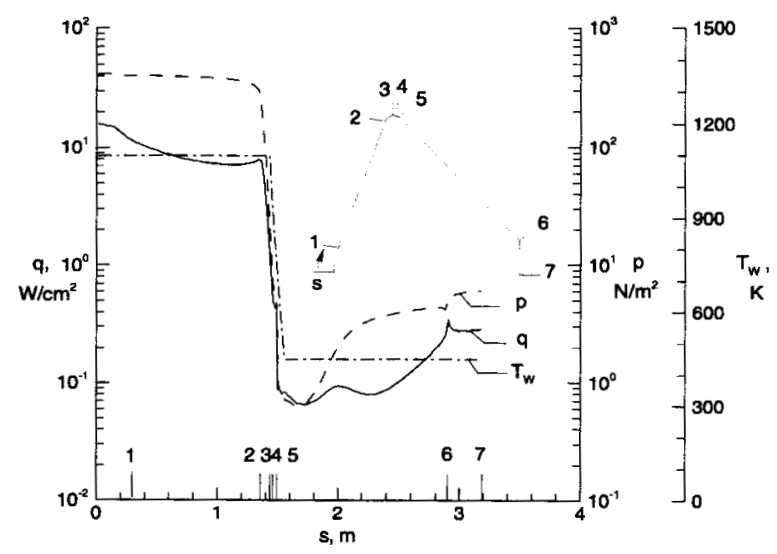

(a) Forebody and afterbody results.

Fig. 11 Heating rate, pressure, shear stress and wall temperature distributions for Mars Pathfinder at $65 \mathrm{~km}$ and $\alpha=0^{\circ}$.

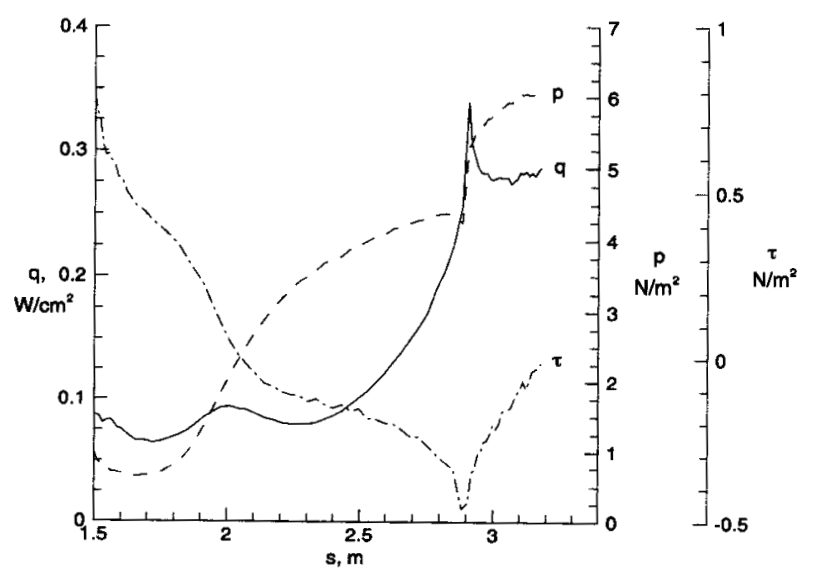

(b) Afterbody results.

Fig. 11 Concluded. 


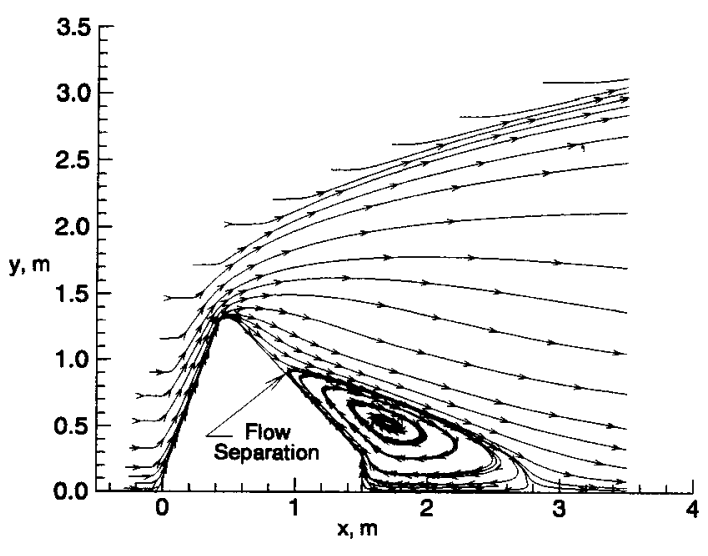

(a) Streamlines.

Fig. 12 Flowfield quantities for Mars Pathfinder at $65 \mathrm{~km}$ and $\alpha=0^{\circ}$.

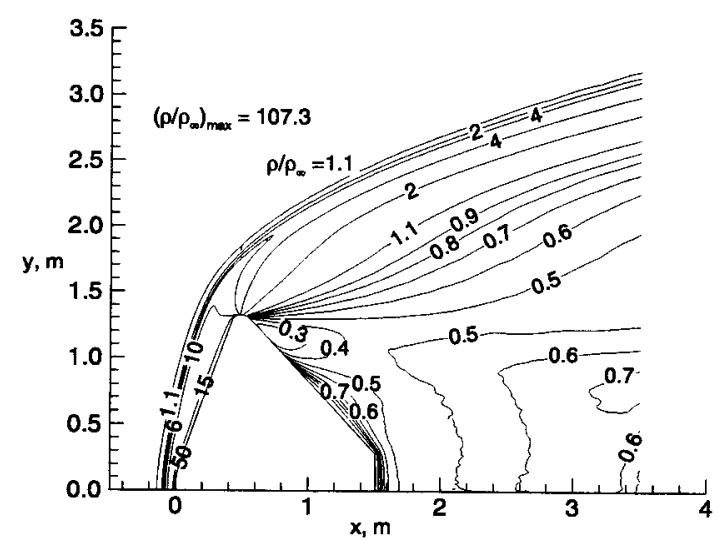

(b) Density contours.

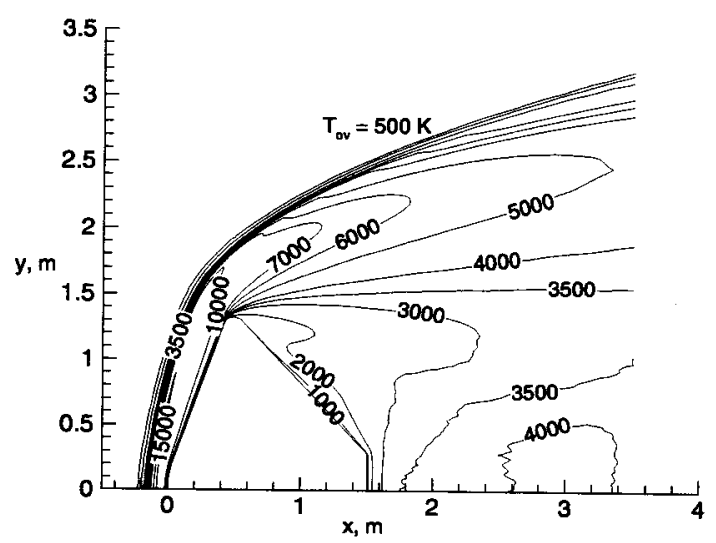

(c) Overall kinetic temperature countours.

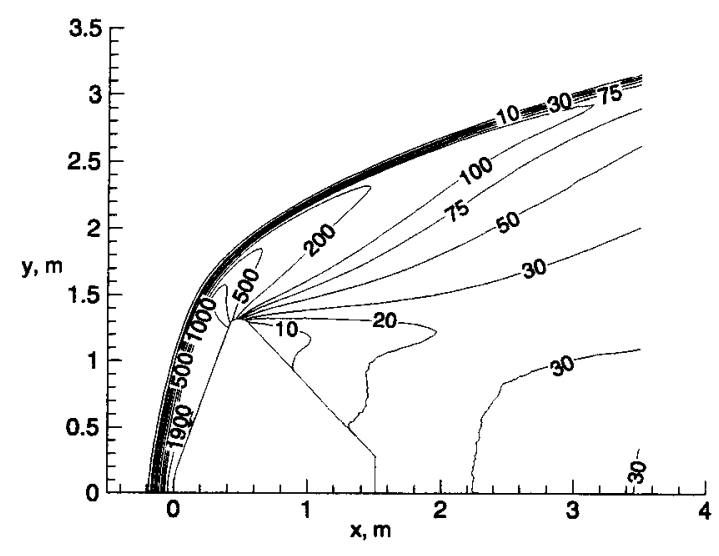

(d) "Pressure like" contours $\left[\mathrm{nT}_{\mathrm{ov}} /(\mathrm{nT})_{\infty}\right]$.

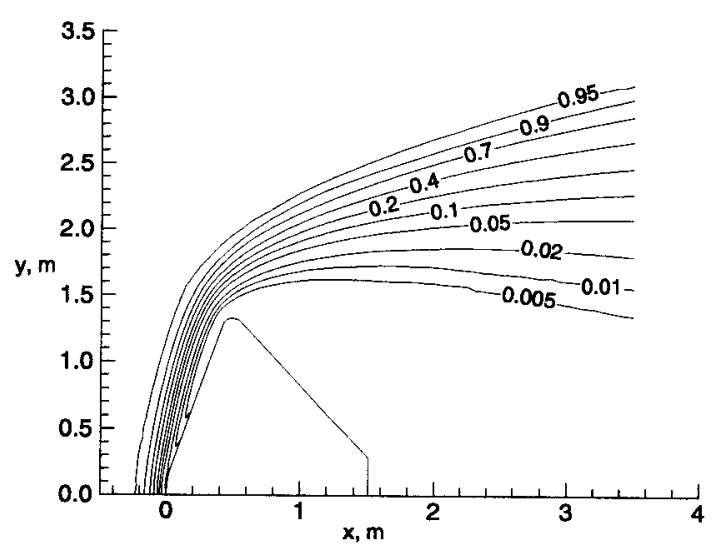

(e) Mole fractions of $\mathrm{CO}_{2}$.

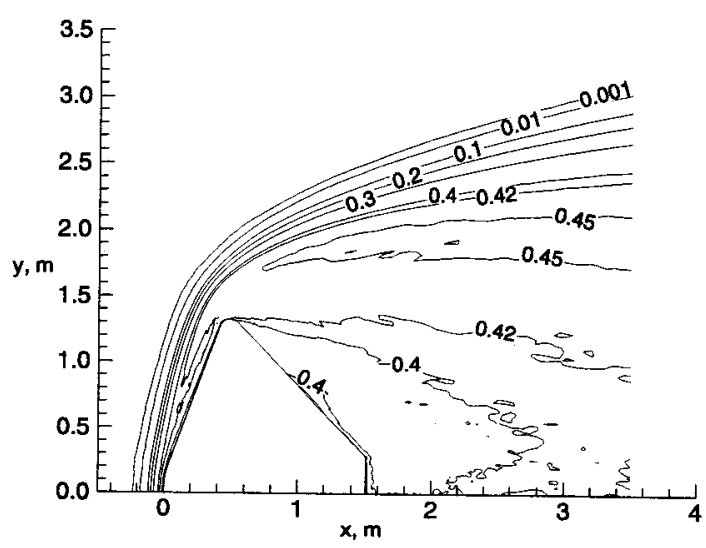

(f) Mole fractions of CO. 


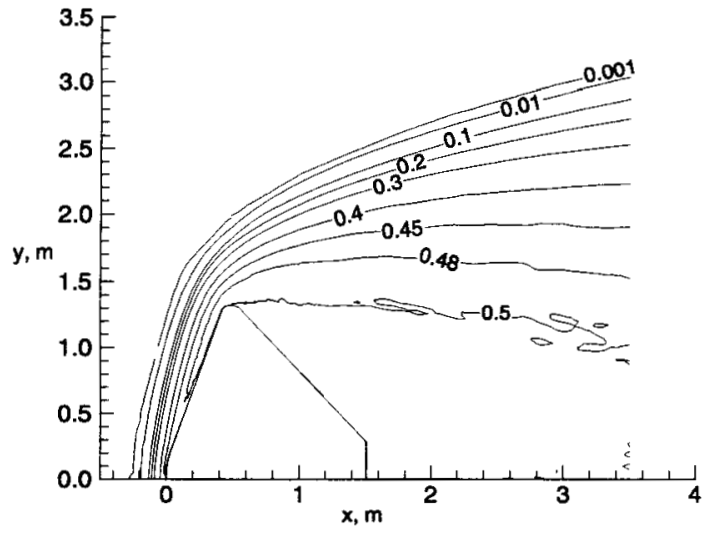

(g) Mole fractions of atomic oxygen.

Fig. 12 Concluded.

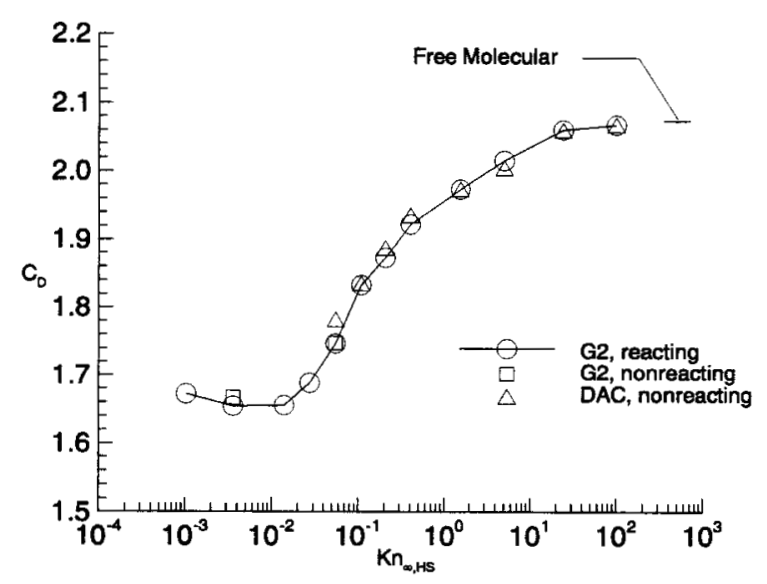

Fig. 13 Comparison of calculated drag coefficient at $\alpha=0^{\circ}$.

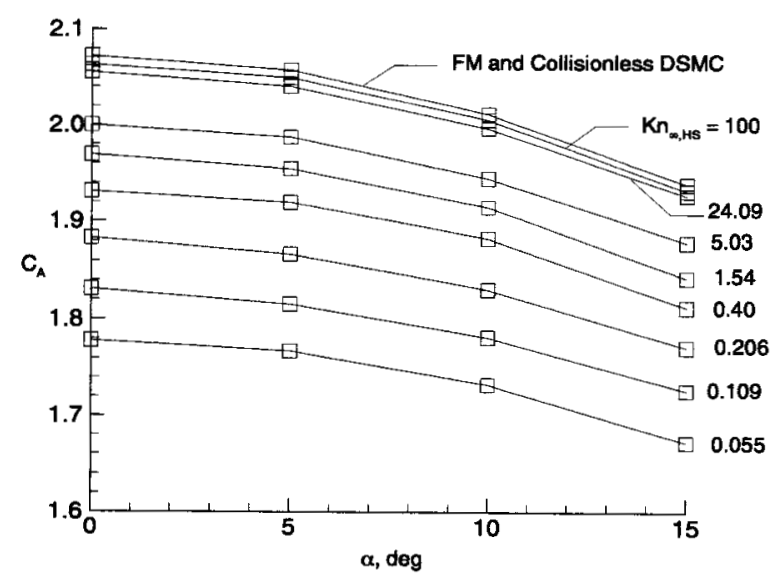

(a) Axial coefficient.

Fig. 14 Pathfinder aerodynamic coefficient as a function of angle of attack and rarefaction.

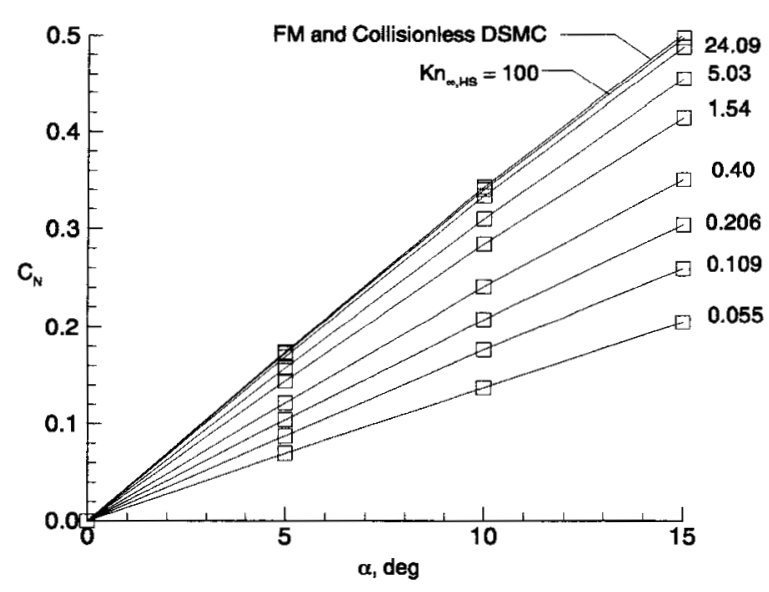

(b) Normal coefficient.

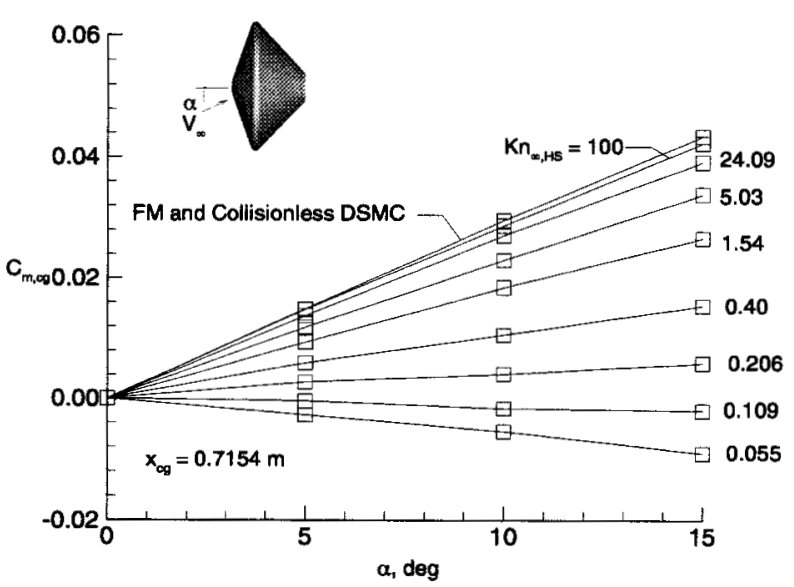

(c) Moment coefficient about center of gravity.

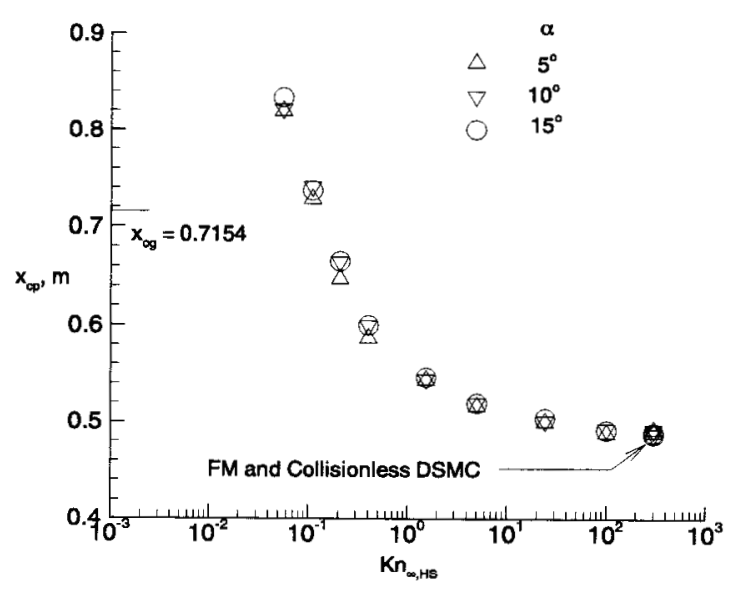

(d) Center of pressure. 


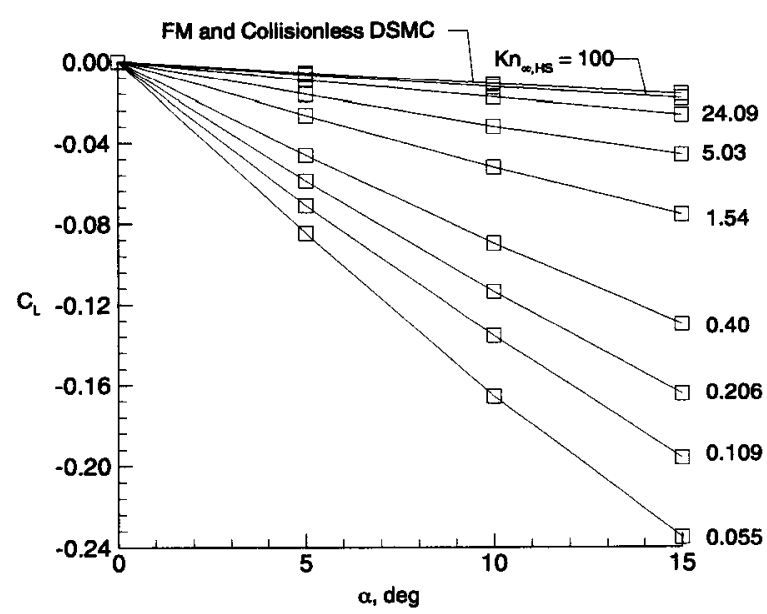

(e) Lift coefficient.

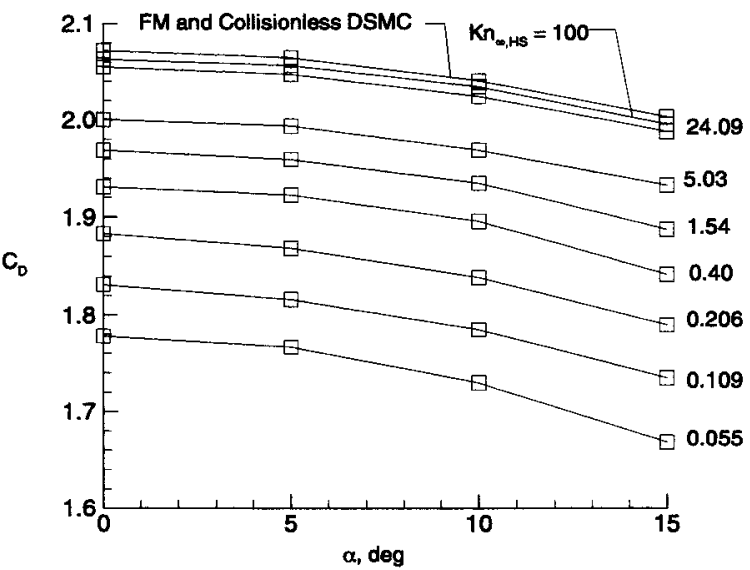

(f) Drag coefficient.

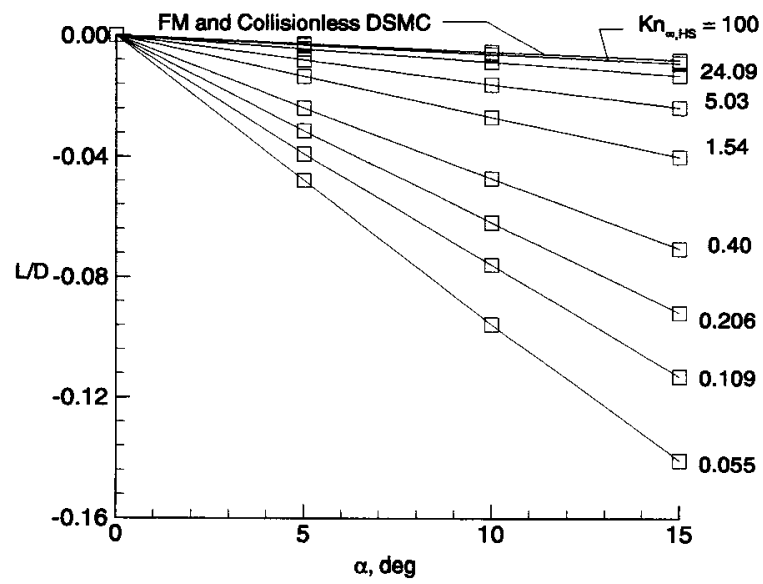

(g) Lift-to-drag ratio.

Fig. 14 Concluded.

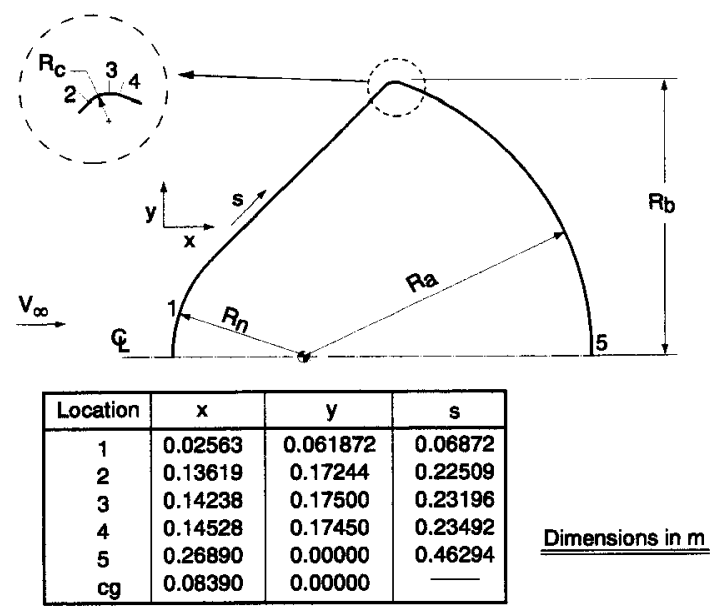

Fig. 15 Mars Microprobe configuration $\left(R_{n}=0.0875\right.$, $R_{c}=0.00875, R_{a}=0.185$ and $R_{b}=0.175$ ).

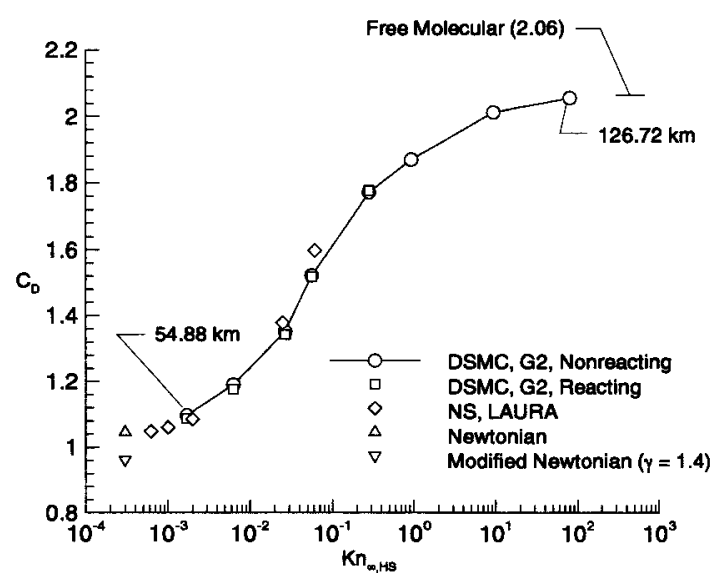

Fig. 16 Mars Microprobe drag coefficient for $\alpha=0^{\circ}$.

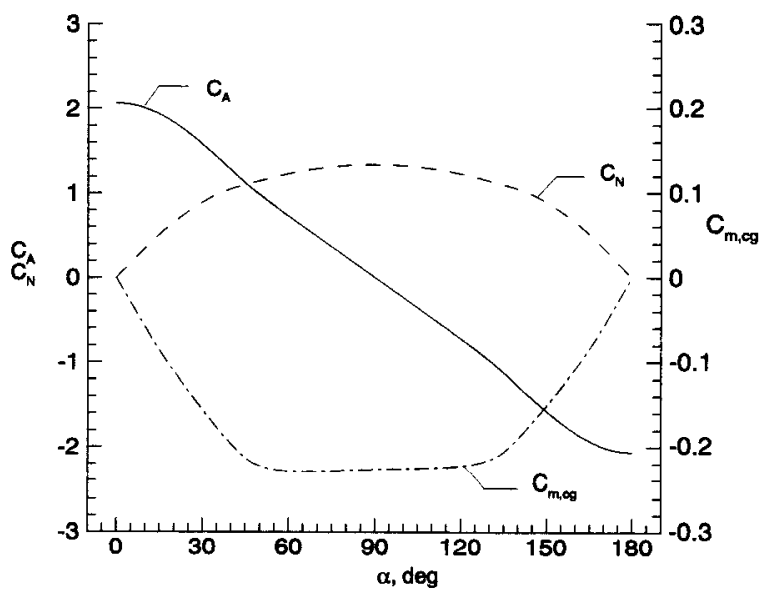

Fig. 17 Microprobe free molecular aerodynamics. 


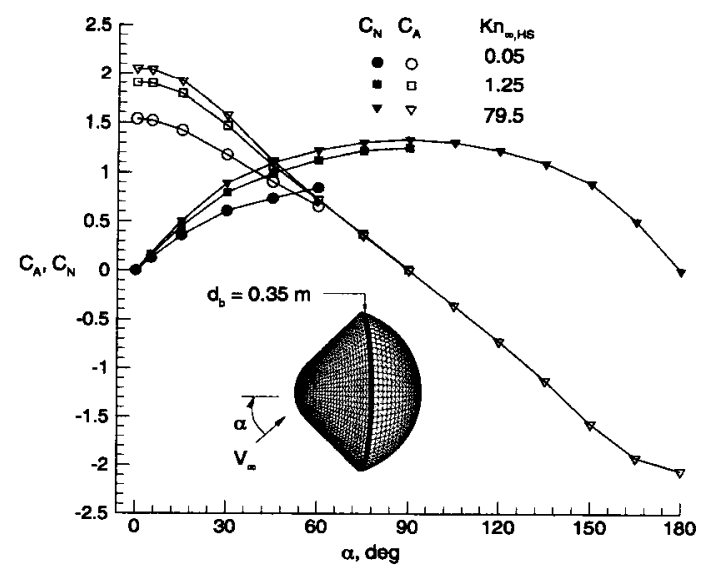

(a) Axial and normal force coefficients.

Fig. 18 Microprobe aerodynamics as a function of rarefaction and $\alpha$.

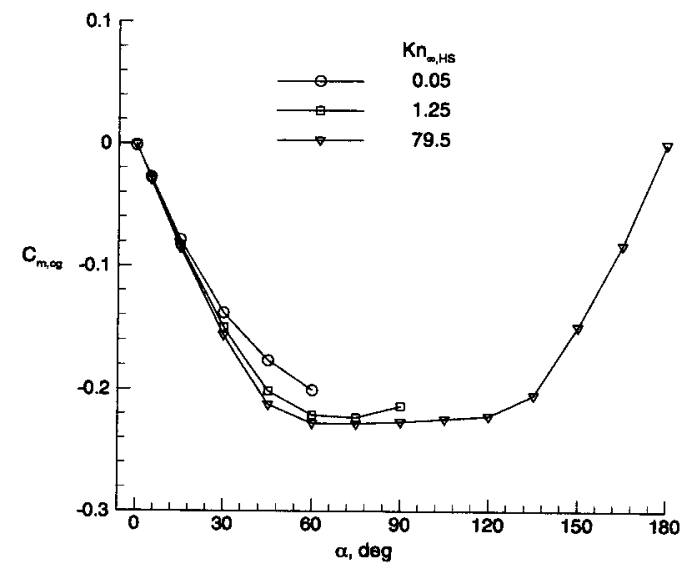

(b) Pitching moment coefficient about center of gravity $(x=0.0839 \mathrm{~m})$.

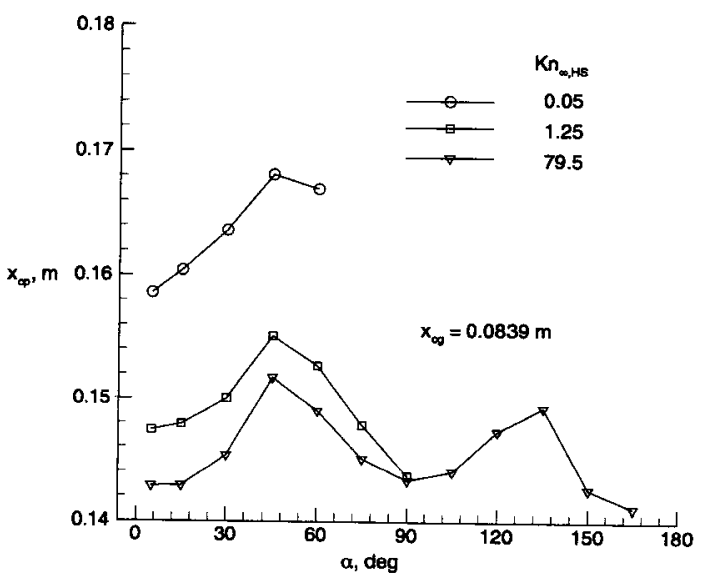

(c) Location of center of pressure w.r.t nose.

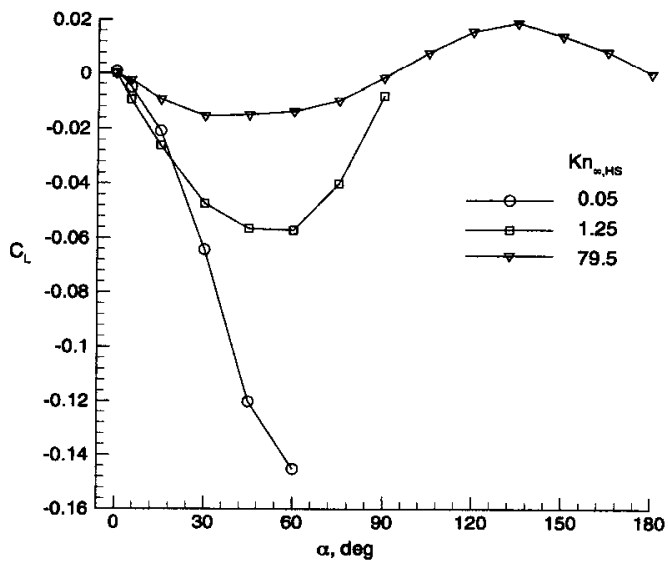

(d) Lift coefficient.

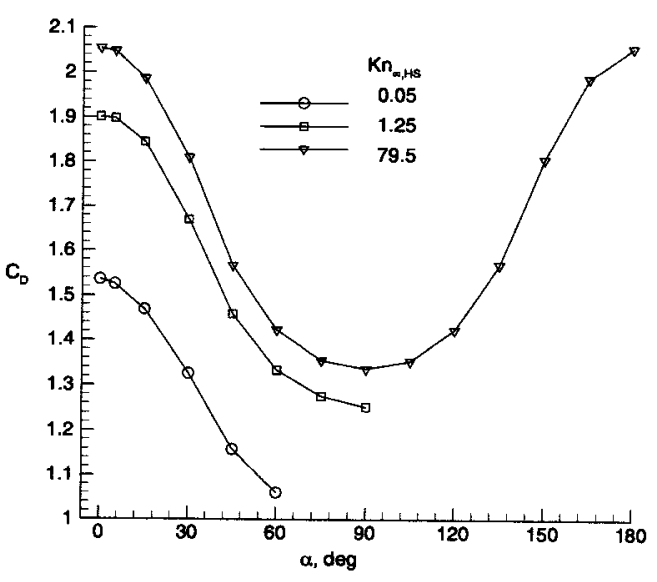

(e) Drag coefficient.

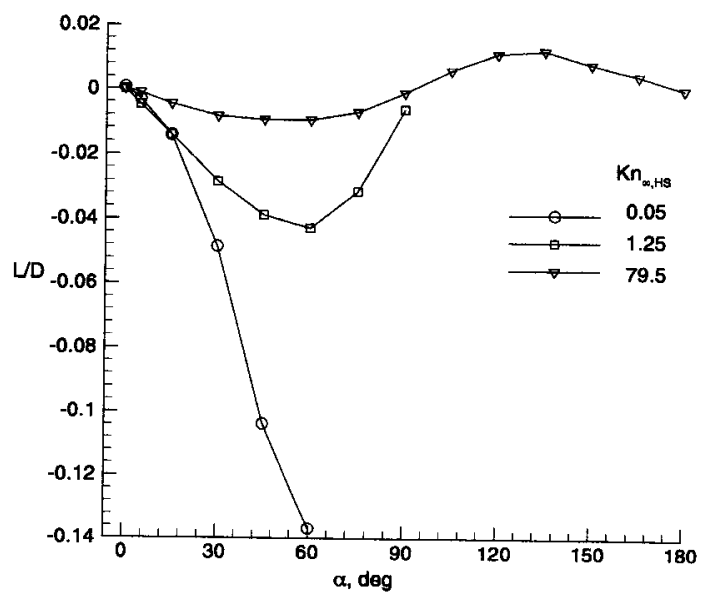

(f) Lift-to-drag ratio.

Fig. 18 Concluded. 


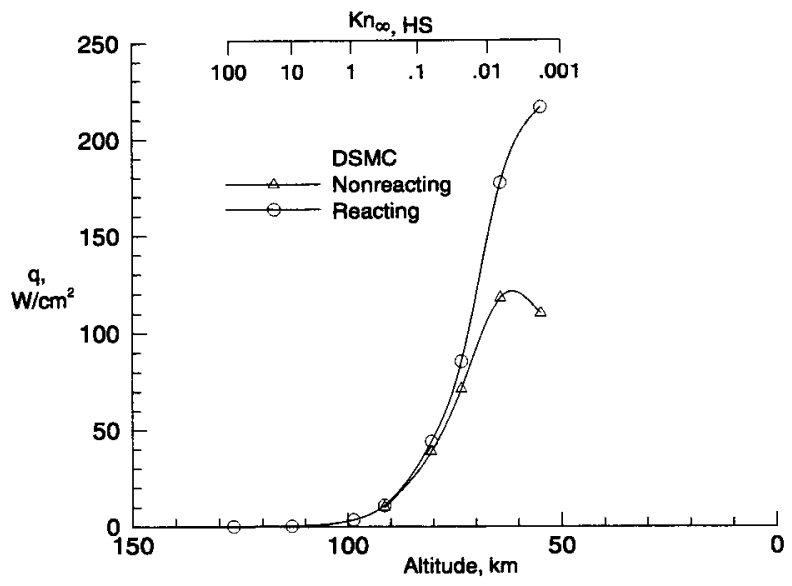

Fig. 19 Effect of nonequilibrium chemistry on stagnation-point heating for Microprobe.

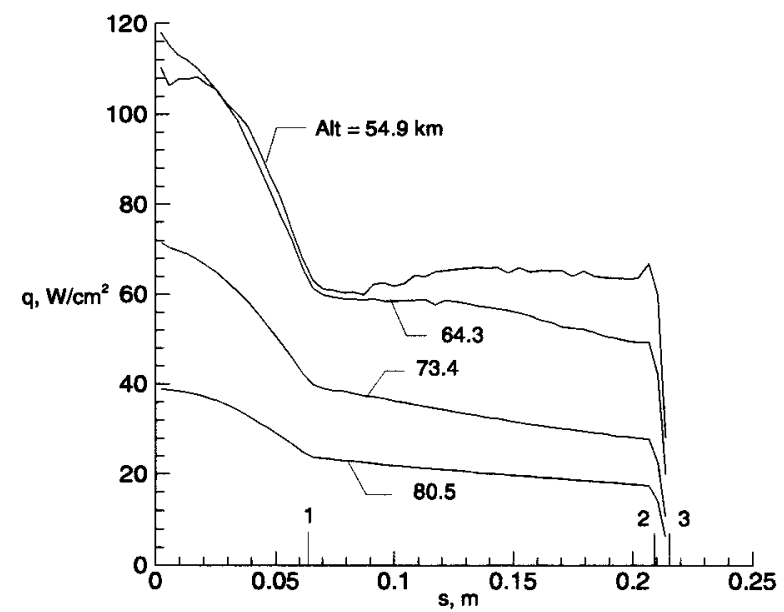

Fig. 20 Microprobe heating rate distributions.

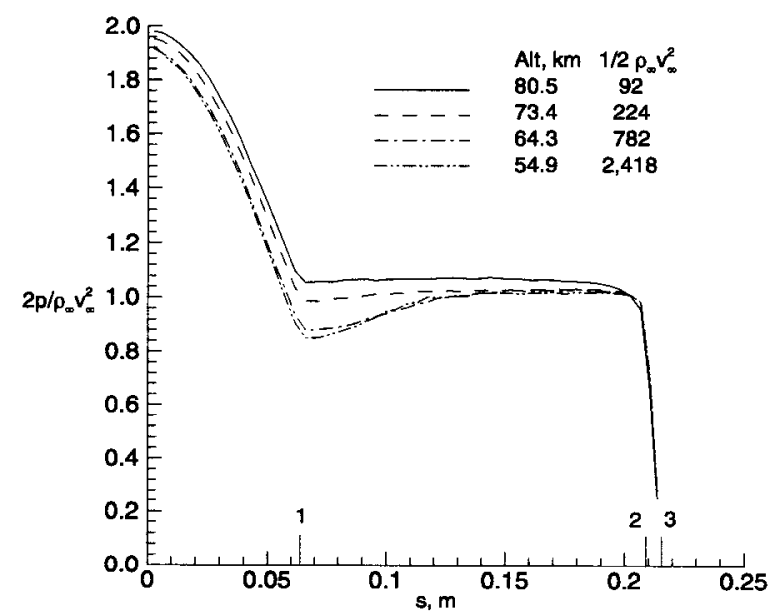

Fig. 21 Microprobe surface pressure distributions.

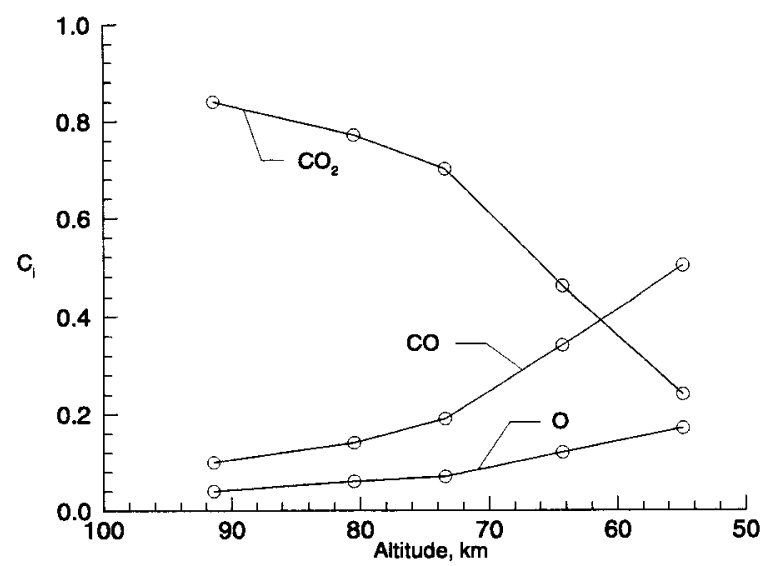

Fig. 22 Mass fraction of dominant species adjacent to forebody stagnation point.

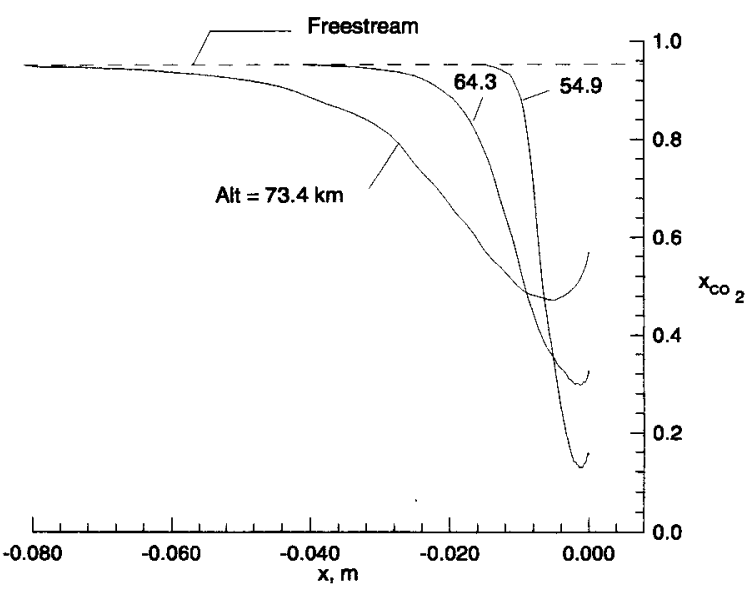

Fig. $23 \mathrm{CO}_{2}$ mole fraction profiles along stagnation streamline for Microprobe. 